\title{
BANCO DE ITENS PARA AVALIAÇÃO DE RACIOCÍNIO DIAGNÓSTICO (BIARD)
}

Tese apresentada à Escola de Enfermagem da Universidade de São Paulo para obtenção do título de Doutor em Enfermagem

Área de concentração:

Enfermagem na Saúde do Adulto

Orientadora:

Prof $^{a}$. Dr ${ }^{a}$. Diná de Almeida Lopes Monteiro da Cruz

\section{SÃO PAULO}

2008 
Nome: Ana Paula Vilcinski Oliva

Título: Banco de itens para avaliação do raciocínio diagnóstico (BIARD)

Tese apresentada à Escola de Enfermagem da Universidade de São Paulo para obtenção do título de Doutor em Enfermagem

Aprovado em:

Banca Examinadora

Prof. Dr.

Instituição:

Julgamento:

Assinatura:

Prof. Dr.

Instituição:

Julgamento:

Assinatura:

Prof. Dr.

Instituição:

Julgamento:

Assinatura:

Prof. Dr.

Instituição:

Julgamento:

Assinatura: 
"O Senhor é meu pastor nada me faltará" Salmo 23:1 
À minha mãe, em reconhecimento aos obstáculos superados em sua trajetória.

Ao Key, por todo seu amor e apoio. Pela sua presença em minha vida sem a qual jamais poderia entender a sensação de felicidade.

Aos nossos filhos, Henrique Mitio e Felipe Key, que nasceram do nosso profundo amor - meninos mágicos que mantêm tudo sob perspectiva. 


\section{AGRADECIMENTOS}

Finalmente o dia de escrever esta página! Tantas vezes pensada, mas sempre à espera do momento certo. Procuro certa ordem de "importância" para começar, mas não consigo tal ordem, pois todos me foram importantes nessa trajetória. Penso, então, cronologicamente nos fatos, como já dizia a professora Cibele Andruciolli de Matos Pimenta: "Vamos aos fatos".

Ao meu pai (in memorian).

À minha amiga Keka, por cada momento conseguido a custo para nós, por cada frase proferida, por cada oração, pela sua presença. Obrigada, Senhor, pela sua vida e a de seu adorado filho Pedro Henrique.

À minha querida orientadora Diná, fonte de admiração e inspiração, muito obrigada por esta e por tantas outras oportunidades. Cada conquista profissional minha sempre será dedicada a você. Louvado seja Deus pela sua vida e pelos seus dons.

Ao Prof. Dr. Dalton de Andrade que prontamente abraçou este estudo e pela co-orientação, infelizmente não oficializada.

À Dra. Marjory Gordon, professora emérita do Boston College, Massachussets, EUA, pela disponibilização dos itens do Diagnostic Reasoning Tool (DRT) e pela sua grandiosa contribuição à enfermagem.

À minha Néia, braço direito e companheira de toda hora.

Aos meus queridos Yamá e Yukio........saudades!

Ao Monsenhor Orivaldo Robles, pessoa que me resgatou do vazio e me mostrou o amor de Deus, na vida de Cristo.

À Fabi, por ter me socorrido e amparado tantas vezes.

Às colegas de disciplina, Crê, Maria das Neves, Jussara, Catarina e Cidinha, pelo respaldo na disciplina para que eu pudesse me formar.

Ao Raul e ao Marcus por todo apoio junto ao Key em minhas ausências e pelo refúgio para escrever a tese. 
Oliva APV. Banco de itens para avaliação do raciocínio diagnóstico (BIARD) [tese]. São Paulo: Escola de Enfermagem, Universidade de São Paulo; 2008.

\section{RESUMO}

Este estudo teve como objetivos criar um banco de itens para composição de testes para avaliação do raciocínio diagnóstico, a partir dos itens propostos por Gordon e Plunkett no Diagnostic Reasoning Test e descrever a proficiência no raciocínio diagnóstico de enfermeiras e estudantes de enfermagem. O referencial teórico assumido neste estudo foi a teoria de geração de hipóteses e a Psicometria foi o referencial metodológico utilizado para a seleção dos itens que compuseram o banco. Este estudo foi uma análise secundária das respostas a 35 itens de raciocínio diagnóstico, obtidas de 362 participantes de um estudo primário sendo 142 enfermeiras $(39,2 \%), 212(58,6 \%)$ estudantes de graduação em enfermagem e 8 $(2,2 \%)$ sem informação; 93,4\% mulheres; idade média de 29,5 $\pm 9,4$ anos. As enfermeiras tinham em média $13,9 \pm 8,1$ anos de formadas e $84,8 \%$ dos estudantes cursavam do quinto semestre em diante. Os gabaritos das respostas aos 35 itens foram revisados e codificados, de acordo com o que as respostas do estudo primário foram pontuadas como variáveis dicotômicas. A análise pela TRI, modelo com dois parâmetros, usando o programa BILOG $^{\circledR}$ indicou a exclusão de 4 dos 35 itens e forneceu os parâmetros de dificuldade e de poder de discriminação dos 31 itens restantes. Com esses parâmetros foi criada uma escala de proficiência em raciocínio diagnóstico e foram identificados os itens típicos de cada nível da escala. A análise qualitativa e comparativa dos itens típicos de cada nível permitiu descrever as habilidades diagnósticas requeridas em cada nível segundo a combinação dos seguintes fatores relacionados aos dados apresentados aos respondentes: especificidade das pistas para o diagnóstico mais provável; convergência de pistas em torno do diagnóstico mais provável; tradição do papel de enfermagem evocado pelos dados apresentados, especialização do contexto clínico e quantidade de dados disponíveis em cada item. A escala foi criada em torno de um valor médio igual a 200( \pm 20$)$. Os 31 itens selecionados posicionaram-se entre os níveis 200 e 340, com exceção dos níveis 220 e 340, que permaneceram sem qualquer item. A proficiência média dos enfermeiros da amostra do estudo primário foi $199,7( \pm 13,6)$, a dos estudantes foi 200,3( $\pm 13,3)$ e não houve diferença estatística entre as duas categorias ( $t$-student; $p=0,72$ ). Não houve correlação significativa entre proficiência em raciocínio diagnóstico e anos de profissão para as enfermeiras $(p=0,97)$ e anos de graduação para as estudantes $(p=0,204)$. O banco criado disponibiliza itens para avaliação de proficiência em raciocínio diagnóstico que podem ser aplicados a enfermeiras e estudantes de graduação em enfermagem em diversas situações de avaliação no ensino, pesquisa e assistência. Com a escala criada outros itens poderão ser desenvolvidos, especialmente para avaliar níveis de proficiência abaixo da média. A escala criada merece destaque pela discriminação das habilidades diagnósticas requeridas para o acerto dos itens de cada nível.

PALAVRAS-CHAVE: Julgamento. Enfermagem (classificação). Avaliação em Enfermagem. Diagnóstico de enfermagem. Psicometria. 
Oliva APV. Diagnostic Reasoning Assessment Item Bank - DRAIB [thesis]. São Paulo (SP), Brasil: Escola de Enfermagem, Universidade de São Paulo; 2008.

\begin{abstract}
The purpose of this study were to create an item bank for tests composition to assess diagnostic reasoning from the items proposed by Gordon and Plunkett in Diagnostic Reasoning Test and to describe the proficiency of nurses and nursing students' diagnostic reasoning. The theory of hypothesis generation was the theoretical referential assumed in this study and Psychometry was the methodological referential used to select the items composing the bank. This study was the secondary analysis of the answers to 35 items of diagnostic reasoning, obtained from 362 participants in a primary study. The sample characteristics were: 149 (39.2\%) nurses, $212(58.6 \%)$ nursing students and $8(2.2 \%)$ participants without information; $93.4 \%$ women; average age of $29.5 \pm 9.4$ years old. The nurses had been graduated for $13.9 \pm 8.1$ years on average and the students were at least at their fifth semester. The answers to the 35 items were checked and coded, according to what the answers from the primary study had been marked as dichotomous variables. The analysis by IRT, model with two parameters, using the program BILOG ${ }^{\circledR}$ indicated the exclusion of 4 out of the 35 items and provided the parameters of difficulty and discrimination power of the remaining 31 items. With these parameters, a scale of proficiency in diagnostic reasoning was created and the typical items of each level of the scale were identified. The qualitative and comparative analysis of the typical items of each level permitted describing the diagnostic skills requested in each level according to the combination of the following factors related to the data presented to the interviewees: the specificity of the clue for the most likely diagnosis; the convergence of the clue around the most likely diagnosis; tradition of the role of the nurse evoked by the presented data; specialization of the clinical context and the quantity of the data available in each item. The scale was created around an average value equal to 200( \pm 20$)$. The 31 selected items were between the levels 200 and 340, except for levels 220 and 340 which remained without any item. The average proficiency of the nurses assessed in the primary study's sample was $199.7( \pm 13.6)$, while it was $200.3( \pm 13.3)$ for the students, and there was no statistical difference between the two categories ( $t$-student; $p=0.72$ ). There was no significant correlation between the proficiency in diagnostic reasoning and years of work for the nurses $(p=0.97)$ and years of graduation for the students $(p=0.20)$. The created bank provides items to assess the proficiency in diagnostic reasoning which can be applied to nurses and nursing students in different situations of assessment in teaching, research and assistance. With the created scale, other items can be developed, especially to assess levels of proficiency below the average. The created scale is worth of note for its discrimination of the diagnostic skills required to mark the items of each level right.
\end{abstract}

KEY-WORDS: Judgement. Nursing (classification). Assessment in Nursing. Nursing Diagnosis. Psychometry. 


\section{LISTA DE FIGURAS}

Figura 1 - Componentes do processo de geração de hipóteses, segundo Elstein et $\mathrm{al}^{4}$.

Figura 2 - Distribuição do nível de proficiência da amostra estudada

Figura 3 - Correlação entre o nível de proficiência e anos de profissão, São Paulo 2007

Figura 4 - Correlação entre o nível de proficiência e anos de graduação, São Paulo 2007

Figura 5 - Correlação entre o nível de proficiência e média do grau de contato com o conceito diagnóstico de enfermagem, São Paulo - 2007 


\section{LISTA DE QUADROS}

Quadro 1 - Item do Diagnostic Reasoning Test (DRT)

Quadro 2 - Categorias possíveis de respostas segundo o número de acertos nas partes A e $\mathrm{B}$ dos itens

Quadro 3 - Redução das 10 categorias de respostas para 4 categorias

Quadro 4 - Redução de 4 para 2 categorias de respostas

Quadro 5 - Distribuição dos itens segundo nível de proficiência, quantidade de itens em cada nível e número dos itens

Quadro 6 - Itens típicos dos níveis de proficiência em raciocínio diagnóstico

Quadro 7 - Níveis de proficiência da escala segundo características dos itens típicos

Quadro 8 - Descrição dos níveis da escala 


\section{LISTA DE TABELAS}

Tabela 1 - Características da amostra de respondentes do TRD segundo sexo, idade, categoria, São Paulo - 2002

Tabela 2 - Análise descritiva dos itens e valores da correlação bisserial, São Paulo 2007

Tabela 3 - Estimativa dos parâmetros dos itens pela TRI, São Paulo - 2007

Tabela 4 - Posicionamento dos itens, segundo os níveis de proficiência na escala, São Paulo - 2007

Tabela 5 - Características da amostra de respondentes do TRD segundo categoria, tempo de formação e semestre de graduação, São Paulo - 2002

Tabela 6 - Associação entre proficiência em raciocínio diagnóstico e categoria do respondente, São Paulo - 2007

Tabela 7 - Distribuição da amostra de enfermeiros segundo faixas de tempo de formação e proficiência, São Paulo - 2007

Tabela 8 - Distribuição da amostra de estudantes de enfermagem segundo faixas de tempo de graduação e proficiência, São Paulo - 2007

Tabela 9 - Medidas dos graus de contato segundo atividades e categoria (enfermeira/estudante), São Paulo - 2002 


\section{SUMÁRIO}

1. INTRODUÇÃO 13

1.1 A PRÁTICA DIAGNÓSTICA E O PROCESSO DE ENFERMAGEM 14

1.2 A PESQUISA SOBRE JULGAMENTO CLÍNICO E RACIOCÍNIO DIAGNÓSTICO 16

2. OBJETIVOS 26

3. REFERENCIAL TEÓRICO 27

4. REFERENCIAL METODOLÓGICO 32

5. MÉTODOS 34

5.1. PREPARO DOS DADOS PRIMÁRIOS 34

5.1.1. Materiais 34

5.1.2. Amostra 36

5.1.3 Procedimentos 37

5.2. CRIAÇÃO E INTERPRETAÇÃO DA ESCALA 41

5.2.1 Análise dos itens 41

5.2.2 Criação e interpretação da escala de raciocínio diagnóstico 43

5.3. ANÁLISE DA PROFICIÊNCIA EM RACIOCÍNIO DIAGNÓSTICO 44

6. RESULTADOS 46

6.1 CRIAÇÃO E INTERPRETAÇÃO DA ESCALA DE PROFICIÊNCIA EM RACIOCÍNIO DIAGNÓSTICO 46

6.2 NÍVEIS DE PROFICIÊNCIA E VARIÁVEIS SELECIONADAS

7. DISCUSSÃO 62

8. CONCLUSÃO 69

Referências $\quad 71$ 


\section{APRESENTAÇÃO}

A complexidade da avaliação do raciocínio diagnóstico é um desafio para a enfermagem na construção do conhecimento. Expressões como grau de proficiência ou capacidade cognitiva, ou mesmo raciocínio diagnóstico, são usadas para indicar "componentes ocultos" do processo que se inicia com o levantamento de pistas e se estende até a decisão sobre qual diagnóstico é o mais provável dentre as hipóteses levantadas. Neste trabalho, a denominação adotada foi raciocínio diagnóstico. $\mathrm{O}$ problema de pesquisa trata de como avaliar o raciocínio diagnóstico, de modo padronizado e confiável. A proposta foi desenvolver um banco de itens para avaliação do raciocínio diagnóstico, criando-se uma medida padronizada com suporte da Teoria da Resposta ao Item (TRI). Para tanto, foram estudados os itens propostos por Gordon e Plunkett ${ }^{1}$, no instrumento intitulado Diagnostic Reasoning Tool (DRT), que consiste na operacionalização do construto Raciocínio Diagnóstico.

O banco de itens servirá tanto ao corpo docente das instituições de ensino, quanto aos gestores de serviços de saúde, permitindo conhecer os níveis de proficiência de estudantes de enfermagem e das enfermeiras e acompanhar a evolução de seus desempenhos. A revisão da literatura no campo do raciocínio diagnóstico, abrangendo as definições, classificações, métodos de avaliação e medição e indicadores forneceram suporte para este estudo.

\footnotetext{
${ }^{1}$ Gordon M, Plunkett E. Psychometric properties of a diagnostic reasoning instrument [resumo do projeto sobre avaliação do raciocínio diagnóstico de enfermeiras]. Boston, 1999.
} 
INTRODUÇÃO 


\section{INTRODUÇÃO}

As tarefas de cuidados executadas ou prescritas pelas enfermeiras são decorrentes de um processo de elaboração mental que envolve a coleta de dados e a escolha de decisão sobre o que fazer com os problemas de saúde levantados. Ter ciência desse fato pode não ser comum a todas as enfermeiras. O tipo de formação, a rotina de trabalho ou mesmo a falta de oportunidade de reflexão sobre o que e como se pensa, tira da enfermeira a chance de perceber-se raciocinando clinicamente e, como fruto disto, tomando decisões.

As classificações de enfermagem trazem importantes oportunidades para mudanças nesse cenário. Apesar do fato de a atividade de levantamento de necessidades de cuidados fazer parte da atuação da enfermeira, o uso de classificações exige habilidades clínicas, nunca antes observadas. No modelo tradicional de levantamento de problemas, uma intervenção é sugerida para cada problema identificado. Com o uso de classificações, para que um diagnóstico de enfermagem seja declarado, um conjunto de sinais e sintomas deve ser identificado e, para que esse conjunto seja formado adequadamente, deve-se ter habilidade em levantar e agrupar os dados relevantes. Executar o cuidado usando as classificações também requer mudanças no desempenho da enfermeira sob vários aspectos, começando pelas exigências em declarar um diagnóstico e responsabilizar-se em conduzir o tratamento e pelas demandas de cuidados direcionadas por padrões de respostas humanas e não mais por sinais e sintomas de diagnósticos médicos. As intervenções de enfermagem são estabelecidas, levando-se em consideração os resultados propostos junto ao paciente, as habilidades da enfermeira em desempenhar determinada intervenção e a disponibilidade de recursos de cada instituição ou unidade.

O processo de pensamento utilizado para desempenhar todas as atividades acima descritas é denominado Raciocínio Clínico e pode ser definido como um processo que utiliza habilidades cognitivas dedutivas e indutivas, para simultaneamente coletar e avaliar dados ${ }^{1}$. É um componente essencial da prática da enfermagem, usado para assimilar informações, analisar e agrupar dados e tomar decisões sobre o cuidado dos pacientes. Nesse processo de raciocinar clinicamente, a 
enfermeira deve saber reconhecer os diagnósticos mais relevantes em determinada situação, que chamaremos de Raciocínio Diagnóstico. Neste projeto, o raciocínio diagnóstico é um tipo de raciocínio clínico que tem como finalidade a declaração de um título diagnóstico que melhor expresse a resposta do indivíduo ao seu estado de saúde.

\subsection{A PRÁtICA DIAGNÓSTICA E O PROCESSO DE} ENFERMAGEM

Em um estudo de revisão bibliográfica sobre a prática diagnóstica em enfermagem, Lee, Chan e Phillips ${ }^{2}$ mostram como há várias denominações usadas para definir esse conceito. Segundo os estudiosos em enfermagem e medicina, a prática diagnóstica é descrita como um Julgamento Clínico ou Raciocínio Diagnóstico. Para esses autores, o raciocínio diagnóstico é um processo ativo de processamento de informação, no qual uma série de julgamentos clínicos é feita durante e após a coleta de dados, determinando julgamentos informais ou diagnósticos formais. Existe, também, a argumentação de que o processo de raciocínio diagnóstico é um modelo de tomada de decisão clínica, envolvendo habilidade intelectual e resolução de problema ${ }^{2}$. Dessas declarações, observamos não só o uso de terminologias diferentes para a descrição da prática diagnóstica, mas também a percepção de uma atividade essencialmente mental, envolvida nesse processo. Entretanto, outros autores ${ }^{2}$ acrescentam o aspecto da interação como parte desse processo, pois a decisão diagnóstica somente acontece no encontro com o cliente, durante a troca mútua de informações. Nessa concepção, integram a prática diagnóstica, elementos como a colaboração entre enfermeira e cliente, que exige interação humana e outros elementos psicossociais, além das atividades cognitivas ${ }^{2}$.

Duas revisões sobre a história ${ }^{2,3}$ do processo de enfermagem revelam tendências e transformações influenciadas pelo estágio de desenvolvimento do conhecimento e pelas teorias vigentes em cada período. Segundo Pesut e Herman ${ }^{3}$, a primeira geração do processo de enfermagem aconteceu entre 1950 e 1970, sendo que, no início, ele se propunha a ser uma estrutura para o pensamento em 
enfermagem, pela qual os problemas manifestados pelos pacientes pudessem ser rapidamente levantados e solucionados. Essa abordagem levou o corpo docente a desenvolver uma metodologia para resolução de problemas com base na avaliação, gerando um processo composto por quatro etapas: avaliação inicial (assessment), planejamento, intervenção e avaliação final (evaluation), o qual foi amplamente difundido. Esse método foi muito valorizado, pois enfatizava a necessidade de pensar antes de agir $^{3}$. Porém, conforme as enfermeiras obtinham experiência com essa estrutura e o desenvolvimento do conhecimento em enfermagem ocorria paralelamente, começou-se a perceber que o processo, apesar de estruturar o trabalho da enfermeira, era totalmente calcado em classificações médicas, levando a lacunas no cuidado. Essa percepção levou as enfermeiras a questionarem qual o domínio específico da prática da enfermagem e a uma nova geração do processo de enfermagem ${ }^{3}$.

Para Pesut e $\operatorname{Herman}^{3}$, a segunda geração do processo de enfermagem aconteceu entre 1970 e 1990, sendo denominada de Diagnóstico e Raciocínio. Com a inclusão do diagnóstico de enfermagem, o processo ganhou mais uma etapa e uma perspectiva racionalista, pois as enfermeiras começaram a ser estimuladas a explicitarem seus julgamentos ou tomada de decisão ${ }^{2,3}$. Os anos 70 sofreram a influência das teorias estatísticas, entre elas o teorema de Bayes e a teoria da probabilidade, enfatizando ainda mais as ações racionais e lógicas (fundamentação teórica) ${ }^{2}$. Porém, devido à escassez de dados em enfermagem, as enfermeiras apresentaram dificuldade em generalizar suas possibilidades ${ }^{2}$. Na década de 80, continuou-se a busca por uma perspectiva teórica, visto a dissonância entre as teorias estatísticas e a prática de enfermagem. Nesse período Elstein et al. ${ }^{4-6}$, usando a teoria do processamento de informações como uma estrutura teórica, publicaram seus estudos sobre o processo utilizado por médicos no alcance de uma decisão diagnóstica, que ficou denominada como teoria da geração de hipóteses. $\mathrm{Na}$ enfermagem, Carnevali ${ }^{7}$, Tanner $^{8}$ e Tanner et al. ${ }^{9}$ e Gordon ${ }^{10,11}$ examinaram estratégias da geração de hipóteses em estudantes de enfermagem e enfermeiras, na tentativa de levantar o caminho pelo qual a informação é gerada e usada e as hipóteses geradas e testadas. 
Paralelamente a essas preocupações, a década de 1980 também foi marcada pelo movimento à procura de resultados em saúde. O enfoque não era mais nos problemas e diagnósticos, mas sim na especificação de medidas de resultados, sendo mais uma justificativa para a busca de um novo modelo de raciocínio que auxiliasse os profissionais a raciocinarem mais efetivamente ${ }^{3}$.

A terceira geração do processo de enfermagem se inicia nos anos 90 e se estende até o presente ${ }^{3}$, sendo denominada como especificação de resultado e testagem. O desenvolvimento dos sistemas de classificações de resultados e intervenções em enfermagem tem gerado avanços no conhecimento e, conseqüentemente, a necessidade de um novo modelo para a prática clínica ${ }^{3}$.

\subsection{A PESQUISA SOBRE JULGAMENTO CLÍNICO E} RACIOCÍNIO DIAGNÓSTICO

O conceito de julgamento clínico é usado quase como um sinônimo de raciocínio diagnóstico. Os autores o utilizam quando querem se referir a uma habilidade, cujo ensino está mencionado nos currículos de graduação. Numa revisão bibliográfica sobre o ensino do julgamento clínico em enfermagem, Tanner ${ }^{12}$ avaliou trabalhos publicados entre os anos de 1966 e 1986. Nesse estudo, a autora utilizou a seguinte definição de julgamento clínico:

Séries de decisões feitas pelas enfermeiras na interação com o cliente, referentes ao tipo de observações a serem feitas na situação do cliente, à avaliação dos dados observados e à derivação do significado (diagnóstico) e ações de enfermagem que devem ser realizadas com o cliente ou no seu interesse $^{12}$.

Para estruturar a análise, a autora classificou os estudos de acordo com o objetivo principal. Dos 53 estudos levantados, 19 descreveram os processos de julgamento clínico, 12 foram pesquisas metodológicas, testando cinco medidas de comportamento em julgamento clínico, 5 estudos avaliaram a efetividade dos métodos de ensino, no desempenho em julgamento clínico de estudantes e enfermeiras e 17 estudos identificaram os fatores associados com desempenho em julgamento clínico ${ }^{12}$. 
Tanner $^{12}$ observou uma preocupação comum entre os investigadores, relacionada à necessidade de se entender os processos de julgamento clínico para o adequado desenvolvimento de métodos de ensino. Dentre os aspectos mais explorados para o entendimento desses processos estavam:

a) $\mathrm{O}$ modo como se processa a competência individual, relacionada a quais observações fazer, na identificação dos problemas de saúde, provenientes dessas observações, e nas decisões das ações mais adequadas;

b) O modo como a competência progride, do nível iniciante para o nível experiente.

Os primeiros estudos que trataram da capacidade individual em levantar dados e identificar problemas e ações adequadamente são de 1966 e 1967 e referemse a cinco artigos de Hammond ${ }^{13}$ e Hammond et al. ${ }^{14-17}$ sobre o processo de inferência clínica na enfermagem. Essas publicações apresentaram os seguintes delineamentos: uma abordagem teórica para a análise das tarefas cognitivas desempenhadas pelas enfermeiras ${ }^{13}$; a análise do uso de unidades de informação em várias tarefas cognitivas no cuidado de enfermagem ${ }^{14}$; os tipos, freqüência e características das tarefas cognitivas realizadas pelas enfermeiras ${ }^{15}$; a descrição de uma técnica para avaliação do comportamento de busca de informação de enfermeiras ${ }^{16}$; e o processo usado por enfermeiras na revisão de seus julgamentos sobre o estado de saúde do paciente ${ }^{17}$. Nos dois últimos artigos, Hammond et al. ${ }^{16,17}$ introduziram duas perspectivas teóricas ao estudo do julgamento clínico em enfermagem, são elas a Teoria do Alcance de Conceito (Concept Attainment Theory) e a Teoria de Decisão Estatística (Statistical Decision Theory). Dos artigos levantados por Tanner ${ }^{12}$, três deles ${ }^{11,18,19}$ investigaram o uso da teoria do alcance de conceito como uma estrutura de trabalho, porém nenhum deles identificou claramente sua aplicabilidade no julgamento clínico. Os modelos de decisão estatística que apareceram no levantamento de Tanner $^{12}$ foram: o Teorema de Bayes e a Teoria da Utilidade. O Teorema de Bayes descreve um caminho no qual os julgamentos podem ser revisados à luz de novas informações. Hammond et al. ${ }^{17}$ levantaram que enfermeiras tendem a revisar probabilidades na direção sugerida pelo teorema, mas a quantidade de revisão foi muito menor do que a prescrita pelo modelo. A Teoria da Utilidade descreve a seleção das ações, baseada na indicação 
subjetiva do valor de certos resultados e da probabilidade de ocorrência desses resultados, dadas certas ações. Nesse levantamento ${ }^{12}$, um estudo usando essa teoria confirmou que julgamentos intuitivos de enfermeiras correspondem às ações prescritas pelo modelo na maioria dos $\operatorname{casos}^{20}$.

Quatro estudos ${ }^{9,21-23}$ abordaram uma terceira estrutura teórica, a Teoria do Processamento de Informação, também utilizada em estudos sobre o julgamento clínico. Dois deles ${ }^{22,23}$ descreveram o uso de uma abordagem "oportunista", em oposição à sistemática, para o planejamento do cuidado de enfermagem. A estratégia oportunista, usada por peritas em tarefas mais complexas, conserva recursos limitados de processamento de informações.

No levantamento de Tanner $^{12}$, a abordagem indutiva também apareceu como perspectiva teórica em pesquisas relacionadas ao julgamento clínico em enfermagem $^{24-26}$. Baumann e Bourbonnais $^{24}$ identificaram, por entrevista semiestruturada, os fatores que influenciam a tomada de decisão de enfermeiras de cuidado crítico e os resultados indicaram que conhecimento e experiência são os dois fatores mais importantes que influenciam a rápida tomada de decisão, mas a base teórica das decisões foi difícil de ser levantada pelas enfermeiras que fizeram parte do estudo. Ainda na enfermagem em cuidados críticos, Pyles e Stern ${ }^{26}$ investigaram a detecção precoce e prevenção do choque cardiogênico em pacientes com infarto agudo do miocárdio e, aos resultados das entrevistas, aplicaram a Teoria da Gestalt para explicar o processo cognitivo usado por esses profissionais ao fazerem uma avaliação e julgamento. As enfermeiras novatas aprendem a fazer avaliações, diagnósticos e julgamentos relacionados aos cuidados, observando as enfermeiras mais experientes que as apóiam e ensinam numa relação tipo preceptoria.

Estudos sobre a progressão da competência do nível iniciante para o nível experiente foram realizados, com base na Teoria do Processamento de Informações e também por abordagem indutiva. Westfall et al. ${ }^{21}$ analisaram o processo de ativação de hipóteses em testes de simulação de pacientes, porém os resultados sugeriram que a área de inferência clínica é mais complexa que a tradicionalmente vista e que não houve achado suficiente para concluir que o modelo identificou o processo de raciocínio diagnóstico desempenhado por enfermeiras e alunos de graduação. Dois estudos de Corcoran $^{22,23}$ mostraram diferenças no plano de cuidados entre 
enfermeiras, experientes e inexperientes, de hospitais psiquiátricos na habilidade em modificar o plano, dependendo da complexidade da tarefa. A quantidade de informação obtida foi estudada por Broderick e Ammentorp ${ }^{27}$ com o objetivo de levantar diferença, entre enfermeiras experientes e novatas, em identificar problemas de saúde e as enfermeiras experientes levantaram mais dados e indicaram mais problemas do que as novatas.

Esses poucos estudos mostraram diversas perspectivas teóricas e Tanner ${ }^{12}$ concluiu que, em vinte anos de pesquisa, nenhuma teoria havia sido investigada suficientemente para concluir se poderia ser apoiada, refutada ou se necessitaria de revisão.

Outro aspecto observado por Tanner ${ }^{12}$ foi a disponibilidade de instrumentos para a avaliação do desempenho clínico. O formato mais comumente usado foi o Gerenciamento do Problema do Paciente (Patient Management Problem - PMP), que é um teste de simulação escrito, originalmente descrito por McGuire e Babbott ${ }^{28}$, no qual o respondente é apresentado a uma descrição de um paciente e é exigido que se façam julgamentos sobre que tipos de dados obter e quais ações programar. O trajeto através do problema é determinado pelas escolhas do respondente.

Nos doze estudos levantados por Tanner ${ }^{12}$, apareceram diferentes tipos de simulações, mas todas no formato PMP, cujas avaliações foram feitas com amostra de estudantes de graduação e enfermeiras ${ }^{29-39}$. A validade de conteúdo em todos os estudos se deu pelo uso de um painel de peritos que determinou o peso de cada escolha, observação e intervenção selecionada pelos respondentes. A validade de construto foi realizada pelo método de grupo, através das seguintes comparações: entre estudantes de enfermagem e outros estudantes ${ }^{30}$; entre estudantes de enfermagem de um currículo experimental, desenvolvido para melhorar resolução de problemas, e de um currículo tradicional ${ }^{31}$; entre enfermeiras e estudantes ${ }^{35,36}$ e entre grupos de enfermeiras com vários níveis de preparação e experiência ${ }^{31,37}$. Para se verificar a estabilidade dos testes, quatro estudos fizeram o teste-reteste, com intervalos de 3 e 4 semanas $^{28,34}$ e 60 a 90 dias $^{36,37}$. As análises variaram de baixas estimativas $^{28}$ a estatisticamente significante ${ }^{34}$ e uma consistência alta (.71 e .88) nos estudos de intervalos maiores ${ }^{36,37}$. As análises psicométricas dos testes foram realizadas com os escores totais dos respondentes, pela média geral e individual, 
escores de proficiência (segundo critérios estabelecidos por peritos) e por testes tipo Wilcoxon e correlação de Pearson.

Segundo Tanner ${ }^{12}$, os estudos que trataram do desenvolvimento e testagem de medidas de desempenho em julgamento clínico foram limitados, tanto em quantidade, quanto em objetivo e não se pode concluir que os métodos de simulação oferecem medidas válidas do desempenho em julgamento clínico.

Em seu levantamento, Tanner ${ }^{12}$ encontrou apenas cinco artigos que tratavam da descrição de abordagens utilizadas para o ensino do julgamento clínico. Dois estudos apresentaram métodos para auxiliar o processo de avaliação e diagnóstico. $\mathrm{O}$ primeiro $^{40}$ testou a efetividade do uso da árvore de decisão na melhora da acurácia diagnóstica em uma amostra de enfermeiras. O grupo experimental usou um conjunto de árvores de decisão binárias, que lhes permitiu usar a informação sistematicamente e determinar se as características de cada condição estavam presentes. O desempenho do grupo experimental foi significativamente melhor do que o grupo controle. No segundo estudo ${ }^{41}$, os autores examinaram a efetividade do uso de um guia de avaliação estruturada na melhora da habilidade das enfermeiras em identificar cuidados de enfermagem pertinentes. $O$ estudo mostrou não haver diferença entre o grupo experimental e o grupo controle com relação ao número de problemas identificados, mas o grupo experimental apresentou maior quantidade de justificativas para confirmação dos problemas.

Em outros três estudos ${ }^{8,42,43}$, os autores examinaram a efetividade de métodos de ensino, baseados em perspectivas teóricas, em amostras de estudantes de enfermagem. De Tornay ${ }^{42}$ utilizou uma estratégia de ensino específico para auxiliar estudantes na descoberta de conceitos e generalizações, cujo desempenho foi medido pelo formato PMP e não houve significância dos principais efeitos da estratégia de ensino específico entre grupo experimental e controle. Mitchell e Atwood ${ }^{43}$ testaram se o método orientado pelo problema (problem-oriented) era mais eficiente do que o método tradicional para o ensino de estudantes de enfermagem, na identificação e planejamento dos problemas de enfermagem. Os resultados mostraram que os alunos que receberam o método orientado pelo problema não apresentaram maior habilidade na identificação dos problemas dos pacientes que os alunos que não receberam o método, mas os dados indicaram que eles foram aptos em documentar claramente 
suas habilidades e, usando o método orientado pelo problema, eles se mostraram mais habilidosos no planejamento da resolução dos problemas dos pacientes. O terceiro estudo foi da própria Tanner ${ }^{8}$ que, em 1982, desenvolveu um método de ensino experimental, baseado em estudos descritivos de processos de raciocínio diagnóstico e o aplicou em estudantes de graduação. Os escores de habilidade diagnóstica foram derivados das respostas verbais de cinco simulações gravadas em videotape pela autora. Os resultados mostraram que não houve efeito significativo no grupo experimental.

Apesar dos resultados desencorajadores, Tanner ${ }^{12}$ comentou ser prematuro abandonar a esperança de que uma abordagem efetiva para o ensino do julgamento clínico pudesse ser descoberta.

Os fatores associados com a proficiência em julgamento clínico presentes nos estudos analisados por Tanner ${ }^{12}$ foram: nível de educação e anos de experiência em enfermagem; habilidades de pensamento crítico de estudantes e enfermeiras; área profissional (ex: enfermeira, médico, administrador de saúde); o tipo de modelo conceitual usado nos currículos de graduação de enfermagem; e o perfil de personalidade do aluno. Em quatro estudos, os autores usaram simulações com filmes $^{44-47}$, nas quais o respondente listava observações pertinentes e identificava as ações de enfermagem, estipulando razões para cada uma delas e os escores derivaram da comparação das respostas dos sujeitos com um painel de peritos. Em três estudos $^{44,45,47}$, o desempenho das enfermeiras especialistas foi superior ao dos estudantes, porém o desempenho das enfermeiras não melhorou com os anos de profissão, nos profissionais com mais de seis anos de experiência. Um estudo ${ }^{46}$ mostrou que estudantes do curso de graduação em enfermagem e do curso técnico apresentaram desempenho similar, porém não ofereceu dados que explicassem sua argumentação. Uma correlação positiva entre desempenho e grau acadêmico foi encontrada no estudo de Aspinall ${ }^{48}$, usando um estudo de caso simples, porém houve um declínio no desempenho das enfermeiras com mais de dez anos de experiência.

Quatro estudos ${ }^{11,19,8,49}$ avaliaram a relação entre o desempenho em diferentes medidas de julgamento clínico e o desempenho em um teste geral de habilidade de resolução de problema, dos quais três eram o Inventário de Pensamento Crítico de Watson e Glaser (WGCTA). Gordon ${ }^{11}$ usou o Graduate Record Examination e o 
Miller Analogies Test, Matthews e Gaul ${ }^{19}$ utilizaram o Test Mastery Concept e o WGCTA, Holzemer e McLaughin ${ }^{49}$ usaram o Clinical Simulation Tests (CST), o PMP e o WGCTA para avaliar a relação entre as duas medidas, por fim Tanner $^{8}$ utilizou simulações de paciente em videotape, um teste escrito contendo 94 itens, desenvolvido pela investigadora e o WGCTA. Esses estudos não apresentaram relação estatística significante que indicasse um grupo de maior habilidade diagnóstica.

Numa série de estudos publicados nos anos de 1966, 1968 e 1969, Hansen e Thomas $^{50-52}$ e Thomas e Hansen ${ }^{53,54}$ compararam quatro grupos: funcionários públicos de saúde; enfermeiras e enfermeiras supervisoras em saúde pública; docentes de enfermagem; dois grupos de estudantes de graduação em enfermagem e encontraram diferenças nos julgamentos nas áreas de indicação para visita domiciliar e aconselhamento de cuidados médicos. Já McLaughlin et al. ${ }^{37}$ relataram não haver diferença na proficiência entre enfermeiras e médicos em dois testes de simulação, nos quais a prática médica mostrou-se menos voltada aos problemas psicossociais, mas a abordagem patofisiológica foi similar a das enfermeiras.

Dois estudos ${ }^{55,56}$ analisaram categorias diferentes: o tipo de personalidade e habilidades de julgamento clínico ${ }^{55}$ e a habilidade na formulação de diagnósticos de enfermagem e o tipo de currículo ${ }^{56}$, porém Tanner $^{12}$ considerou a base teórica dos estudos fraca e as medidas não sensíveis para detectar diferenças.

Numa avaliação geral do levantamento, Tanner ${ }^{12}$ considerou que os problemas metodológicos mais freqüentes foram nas áreas da amostra e instrumentação. Houve predomínio de pequenas amostras, em um número reduzido de instituições. Os problemas com instrumentação foram relacionados à forte confiança na simulação como um meio de avaliação, tanto do desempenho em julgamento clínico, como na efetividade instrucional ou como um método de elucidar as respostas dos participantes e, assim, descobrir os processos de julgamento clínico. Houve duas preocupações maiores no uso de simulações: as tarefas podiam não ser representativas de tarefas reais de julgamento clínico e a resposta elucidada não ser como aquelas que ocorrem na prática real ${ }^{12}$.

Outro artigo de revisão de literatura ${ }^{57}$, porém de menor abrangência se comparado ao de Tanner ${ }^{12}$, incluiu estudos sobre o pensamento crítico de 
enfermeiras e abordou dois aspectos desse tema. Um deles analisou os estudos que correlacionavam pensamento crítico e julgamento clínico e outro a eficácia da educação de enfermagem em desenvolver habilidades de pensamento crítico.

A relação entre pensamento crítico e julgamento clínico foi descrita em seis artigos de revisão de literatura ${ }^{12,58-62}$ e um artigo de pesquisa ${ }^{63}$, envolvendo amostras de alunos de graduação em enfermagem e enfermeiras.

O primeiro artigo citado na revisão de Follman $^{57}$ é a revisão de Tanner ${ }^{12}$, detalhada anteriormente. Uma segunda revisão ${ }^{58}$ analisou sete tipos diferentes de medidas: Watson-Glaser Critical Thinking Appraisal (WGCTA); Cornell Critical Thinking Test (CCTT); Nursing Process Utilization Inventory (NPUI); Revised Nursing Process Utilization Inventory (RNPUI); Nursing Grade Point Average (GPA); National Council Licensing Examination (NCLEX); Miller Analogy Test. Os resultados não mostraram congruência entre pensamento crítico e julgamento clínico com achados confusos, sem suporte relevante para a educação em enfermagem ${ }^{58}$.

Hickman $^{59}$ comparou os resultados de dez estudos sobre a relação entre pensamento crítico e julgamento clínico, dos quais oito usaram amostras de estudantes de enfermagem e dois estudos amostras de enfermeiras e os resultados mostraram-se contraditórios entre eles. Em todos os estudos, nenhuma relação entre habilidade de pensamento crítico e julgamento clínico foi relatada e, enquanto uns estudos mostravam alto desempenho em julgamento clínico e baixo desempenho em pensamento crítico, outros estudos relatavam achados contrários, porém dois estudos relataram nenhuma correlação significante entre o WGCTA e outras medidas utilizadas para o julgamento clínico. O levantamento de Beeken ${ }^{60}$ apresentou resultados semelhantes, acrescentando falta de relação entre pensamento crítico e nível de habilidade clínica e entre pensamento crítico e habilidade em resolução de problema. O levantamento de Duchscher ${ }^{61}$ sugere que esses resultados podem ser consequiência de inadequado refinamento de instrumentos e delineamento, o que deve ser levado em consideração, frente aos resultados desses levantamentos e da revisão de $\mathrm{Hicks}^{62}$, na qual o padrão ouro para testes de pensamento crítico, o Watson-Glaser Critical Thinking Appraisal (WGCTA), não mostrou relações consistentes em 20 anos de uso em pesquisa sobre medida de julgamento clínico e tomada de decisão. 
Apenas um estudo ${ }^{63}$ encontrou correlação entre o Inventário de Pensamento Crítico de Watson-Glaser e o Exame de Enfermagem da Liga Nacional para Enfermagem Psiquiátrica. Em duas partes desses instrumentos, as correlações foram mais altas do que a maioria dos outros estudos e mais alta do que a maioria de outros testes de pensamento crítico.

Nada pôde ser concluído que indicasse alguma correlação entre o pensamento crítico de enfermeiras e seu julgamento clínico, nem quanto aos instrumentos adequados para avaliação dessas variáveis ${ }^{57}$.

As mudanças nas habilidades de pensamento crítico de estudantes de enfermagem foram avaliadas em dois artigos de revisão de literatura ${ }^{64,65}$ e três artigos de pesquisa ${ }^{66-68}$.

O Inventário de Pensamento Crítico de Watson e Glaser (WGCTA) foi o método de avaliação mais freqüente nos estudos, aparecendo em 18 dos 20 artigos que compuseram a revisão integrativa de $\operatorname{Adams}^{64}$ e na pesquisa de Adams e colaboradores $^{65}$, cuja amostra foi composta por 203 estudantes de enfermagem. Os autores concluem que o WGCTA não é um instrumento de escolha para medidas longitudinais de habilidades de pensamento crítico, na amostra estudada ${ }^{64,65}$.

Um estudo $^{66}$ avaliou a diferença no desenvolvimento do pensamento crítico entre quatro grupos de enfermeiras, em diferentes estágios do processo acadêmico e as percepções de suas habilidades em tomada de decisão, empregando o WGCTA e também avaliou o efeito desse desenvolvimento na prática pela Escala de Tomada de Decisão Clínica em Enfermagem de Jenkins, que é uma escala tipo Likert, composta por 40 itens. Como resultado da primeira análise, não houve diferença significante quanto ao desenvolvimento do pensamento crítico, mas o escore total da escala de Jenkins mostrou diferença significante entre aquelas com e sem grau acadêmico, sugerindo que enfermeiras com uma média de 14 anos de profissão com grau acadêmico foram mais eficazes na tomada de decisão, do que aquelas com 15 anos de profissão, porém sem grau acadêmico ${ }^{66}$.

Hartley e Aukamp ${ }^{67}$ mediram, pelo WGCTA, a habilidade de pensamento crítico de docentes de enfermagem e compararam essas habilidades com valores já estabelecidos para estudantes de enfermagem. As autoras justificaram a investigação pelo fato de os educadores terem tomado para si a responsabilidade em melhorar a 
habilidade de pensamento crítico de seus estudantes. Os resultados mostraram que os docentes apresentaram maior habilidade do que os estudantes $(t=3,13 ; \mathrm{df}=94$, p<.005), com um escore médio de 62.46 pelo WGCTA e desvio padrão $8.34^{67}$.

Outros estudos desenvolveram avaliações com vinhetas ${ }^{68}$, modelo de planejamento de cuidado ${ }^{69}$, National Council Licensing Examination (NCLEX) ${ }^{70} \mathrm{e}$ reflexão da prática profissional ${ }^{71}$.

Ao concluir a revisão ${ }^{57}$, o autor chama a atenção para os critérios de validação dos instrumentos que avaliam pensamento crítico. Ele defende que esses critérios não deveriam ser os testes tradicionais de pensamento crítico desenvolvido nas ciências sociais e comportamentais, mas sim desenvolvidos no contexto da educação de enfermagem. Enfatiza, também, que um desses critérios seja um teste com o uso de vocabulário de enfermagem e medicina ${ }^{57}$.

Os resultados dessas revisões de literatura revelaram que pesquisas envolvendo métodos para o ensino e avaliação das habilidades cognitivas de raciocínio clínico e diagnóstico ainda devem ser desenvolvidas, porém com atenção especial quanto ao tamanho da amostra, local de aplicação, metodologia e critérios de validação dos instrumentos. Esses achados mostram claramente a necessidade de um método de avaliação eficaz, capaz de oferecer resultados seguros sobre os métodos utilizados.

A justificativa para este projeto de pesquisa é que a avaliação da habilidade de enfermeiras ou estudantes de enfermagem em formularem diagnósticos é importante para a avaliação do desempenho e capacidades profissionais, seleção de indivíduos para desempenhar diferentes tarefas, avaliação de métodos de ensino de habilidades clínicas de enfermagem, avaliação currículos e programas de ensino.

A avaliação de habilidades de julgamento clínico, que incluem a habilidade de formular diagnósticos, é um desafio ao ensino e pesquisa em todas as áreas em que o profissional precisa fazer inferências sobre dados observáveis, para decidir sobre suas intervenções. A necessidade de se conduzir o desenvolvimento do raciocínio diagnóstico no ensino é geralmente aceita e vários autores têm proposto estratégias com essa finalidade, visto os resultados das revisões citadas. No entanto, a avaliação dos resultados da aplicação das diferentes estratégias é um aspecto que ainda limita a obtenção de conclusões satisfatórias desses estudos. 


\section{OBJETIVOS}




\section{OBJETIVOS}

Considerando que a operacionalização de variáveis é essencial para o desenvolvimento do conhecimento e a importância do raciocínio diagnóstico na enfermagem, os objetivos deste estudo foram: criar um banco de itens para composição de testes de avaliação do raciocínio diagnóstico e descrever a proficiência no raciocínio diagnóstico de enfermeiras e estudantes de enfermagem. 
REFERENCIAL TEÓRICO 


\section{REFERENCIAL TEÓRICO}

O sucesso do processo diagnóstico depende do modo como a enfermeira adquire e usa a informação. A aquisição e uso da informação clínica estão permeados por elementos que as definem, como por exemplo, a situação na qual esse processo se desenvolve, a complexidade da tarefa a ser executada e atributos do diagnosticador ${ }^{72}$. Portanto, o raciocínio diagnóstico depende do conhecimento teórico, experiência adquirida na prática da enfermagem, capacidade de raciocínio e de julgamento e o bom senso do avaliador.

O comportamento de enfermeiras que coletam, agrupam dados e interpretam os agrupamentos feitos é conduzido por dois tipos de estratégias de raciocínio: as não-analíticas, envolvendo intuição ou reconhecimento de padrões e o raciocínio analítico, concreto e limitado por regras. O primeiro tipo de raciocínio é mais comum em enfermeiras experientes, enquanto o raciocínio analítico, com uso de estratégias diagnósticas parece ser mais característico de enfermeiras novatas ${ }^{10}$.

No raciocínio analítico, o processo diagnóstico é um ciclo de atividades cognitivas e perceptivas envolvendo quatro atividades ${ }^{10}$ :

1. Coleta de informação

2. Interpretação das informações

3. Agrupamento das informações

4. Denominação do agrupamento

A coleta das informações inicia-se na aplicação do histórico de admissão de enfermagem e com o exame físico. Nesse momento, a interação entre enfermeiracliente é importante para a qualidade da informação clínica. Da qualidade dessa interação dependerá qual informação será obtida e, consequentemente, qual julgamento diagnóstico será efetuado.

O processo de interpretação das informações permite ao diagnosticador predizer e explicar os achados e pressupõe duas operações mentais: raciocínio inferencial e julgamento. As informações levantadas serão, então, deslocadas para dentro de padrões previamente aprendidos e estocados na memória, de acordo com a 
interpretação dada a elas. O diagnosticador analisa se os dados se encaixam ou não nos padrões já conhecidos e aplica uma categoria diagnóstica, quando as observações se encaixarem em determinada categoria. A fase de denominação do agrupamento é um ato de julgamento que discrimina os fatos, atribuindo significado para as condições que exigem intervenção de enfermagem ${ }^{10}$.

O referencial teórico assumido neste estudo foi a Teoria de Geração de Hipóteses. Arthur S. Elstein et al. ${ }^{4}$ propuseram uma teoria de investigação médica, cujo aspecto mais relevante é a afirmação de que médicos geram hipóteses diagnósticas específicas, antes de coletar a maioria dos dados. Apesar de essas hipóteses serem geradas precocemente no encontro com o paciente, elas são consideradas satisfatórias.

Os autores ${ }^{4}$ descreveram quatro componentes do processo de geração de hipóteses que, embora estejam descritos em série, podem ocorrer simultaneamente. São eles: 1) observação das pistas inicialmente disponíveis; 2) identificação de elementos problemáticos entre as pistas; 3) associação dos elementos problemáticos à memória de longo-termo e vice-versa, gerando hipóteses e sugestões para investigações e 4) organização informal das hipóteses levantadas, de acordo com a estimativa subjetiva do médico. Os elementos problemáticos são identificados através dos parâmetros afastados da variação de normalidade esperada. Esses elementos são considerados códigos de ligação entre as observações levantadas e o conhecimento adquirido anteriormente, em particular com as taxonomias das doenças. Após as hipóteses terem sido geradas e ordenadas de forma inacabada, elas são sistematicamente testadas na tentativa de confirmar ou rejeitar um conjunto de hipóteses formuladas ${ }^{4}$. 


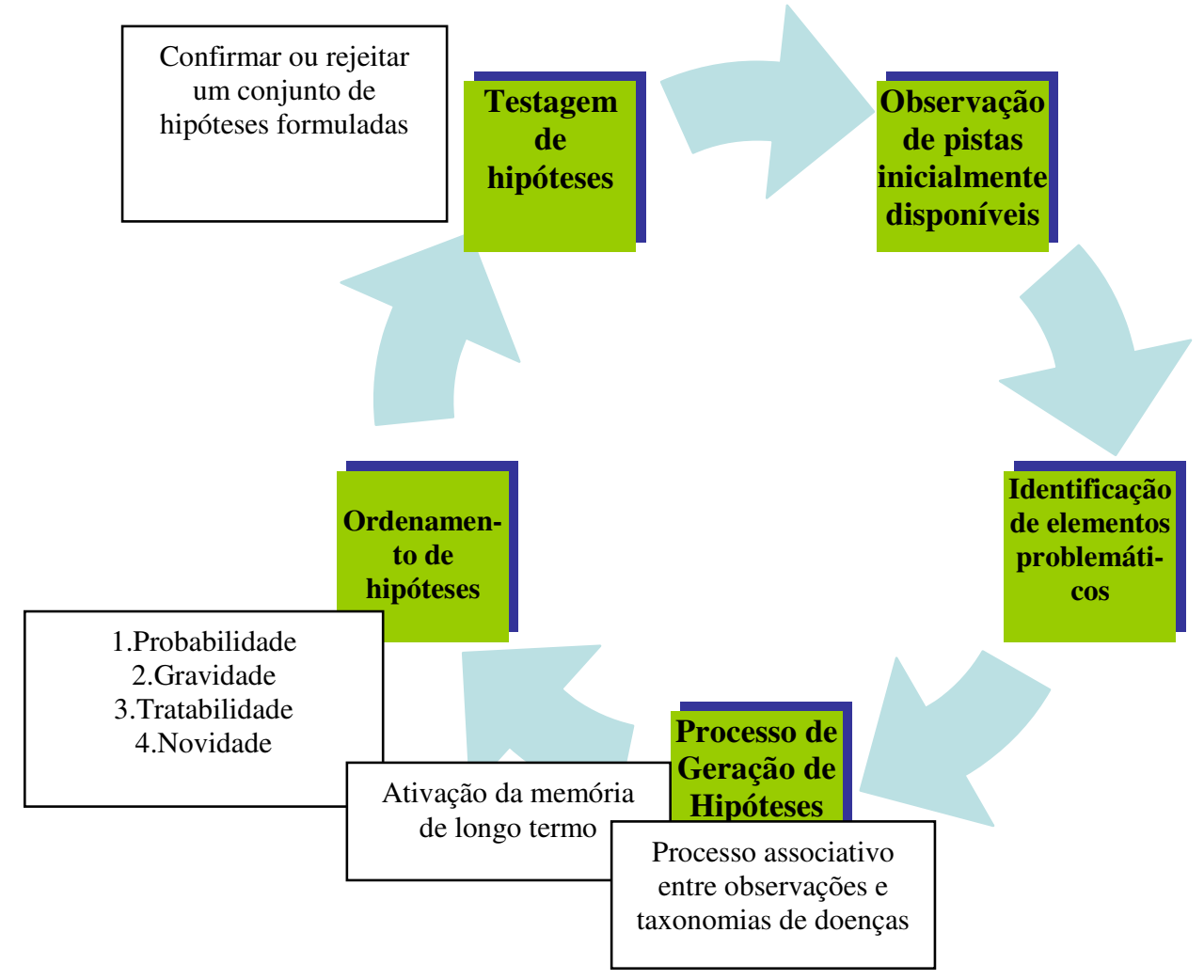

Figura 1 - Componentes do processo de geração de hipóteses, segundo Elstein et al. ${ }^{4}$

A teoria também é consistente quando se discute raciocínio em sistemas abertos. Em um sistema fechado, o problema começa de um ponto conhecido e o pesquisador segue a rota mais apropriada para uma meta específica. Em contraste, a resolução de problema em um sistema aberto, do qual o médico é um bom exemplo, o diagnosticador deverá começar de um ponto conhecido, porém move-se para um ponto terminal, ainda desconhecido. O esforço para deslocar-se sob tal condição é alto. Uma técnica, frequientemente observada para lidar com as demandas do raciocínio dentro de um sistema aberto, é transformar cognitivamente o sistema em uma série de sistemas fechados hipotéticos, com o qual ele pode trabalhar, tanto periodicamente, quanto simultaneamente. Isso significa gerar rapidamente um pequeno número de prováveis pontos terminais e, então, proceder com a 
investigação, testando a conveniência de várias rotas até seu ponto terminal hipotetizado ${ }^{4}$.

O número de hipóteses cogitadas, em qualquer momento do processo, parece ser quatro mais ou menos um, ou seja, varia de 3 a 5 hipóteses, isso devido ao problema da limitada capacidade da memória de curto-termo. Assume-se que hipóteses diagnósticas provisórias são transferidas da memória de longo-termo para a memória de curto-termo, para rápido processamento da informação. Pode-se argumentar que a justificativa para geração precoce de hipóteses seja um caminho para superar os limites da memória de curto-termo ${ }^{4}$.

Na enfermagem, Gordon ${ }^{10}$ discute a geração de hipóteses diagnósticas. Para a autora, a seleção das informações a serem coletadas, a seqüência da coleta e o caminho no qual a informação é usada formam uma seqüência de decisões o que, por definição, é uma estratégia. As decisões finais dessas estratégias são baseadas em hipóteses diagnósticas, pois descrevem as interpretações dos avaliadores sob os dados coletados. Após clarear e verificar as pistas, o diagnosticador pode descartar algumas hipóteses e confirmar ou rever outras hipóteses.

Gordon ${ }^{10}$ comenta existir vários níveis, nos quais o processo diagnóstico se desenvolve. O nível observável compreende: entrevista e exame físico, e a verbalização e registro de um diagnóstico. Mas, parece que a argumentação maior da autora se dá em como explicar esse comportamento, principalmente quando os diagnósticos formulados são válidos e confiáveis. O desempenho de enfermeiras experientes parece ser descrito por explanações não-analíticas, que envolvem intuição e reconhecimento de padrões. As enfermeiras novatas parecem usar o raciocínio analítico e as estratégias diagnósticas aprendidas no período da graduação. O método de teste de hipóteses é uma estratégia útil para ser empregada, enquanto se está aprendendo a reconhecer padrões.

Hipóteses são as alternativas de interpretações dos achados clínicos que a enfermeira consegue realizar. Mas essas hipóteses necessitam de ser elucidadas. Isso significa que não é pelo fato de terem sido geradas, que deverão ser confirmadas; elas devem ser suficientemente examinadas para serem validadas ou não, como também, nesse processo de reavaliação, novas possibilidades diagnósticas podem ser geradas. O sucesso dessa etapa dependerá da forma como os dados foram 
estruturados e organizados na coleta inicial, bem como na busca de informações adicionais que confirmem, descartem as hipóteses, inicialmente geradas, ou direcionem novas hipóteses ${ }^{10}$. 


\section{REFERENCIAL METODOLÓGICO}




\section{REFERENCIAL METODOLÓGICO}

A Psicometria foi utilizada para a seleção dos itens que compuseram o banco final, denominado Banco de Itens para Avaliação de Raciocínio Diagnóstico (BIARD). Ela explica fenômenos cognitivos, usando os números para a representação desses fenômenos ${ }^{73,74}$. A Psicometria é utilizada quando se quer explicar que tipos de comportamentos determinadas respostas expressam ${ }^{73,74}$, por exemplo, o que representa determinado escore de um indivíduo num teste de habilidade diagnóstica, como é o caso deste estudo, isto é, ela auxilia na determinação do nível da habilidade de raciocínio diagnóstico que uma enfermeira ou aluno de graduação deve ter para realizar determinada tarefa. Na Psicometria essa tarefa é denominada de item ${ }^{73,74}$.

Neste estudo, a tarefa, ou seja, o item exigia que o indivíduo gerasse hipóteses diagnósticas e selecionasse a hipótese mais provável, permitindo, assim, estimar qual o grau de proficiência exigido no desempenho de tarefas relacionadas à habilidade clínica, no levantamento dos diagnósticos de enfermagem e explorar possíveis componentes dos diferentes graus de proficiência.

A Psicometria engloba dois modelos: a Teoria Clássica dos Testes (TCT) e a Teoria de Resposta ao Item (TRI). O modelo clássico (TCT) preocupa-se com o escore final do indivíduo em um teste, em outras palavras, qual "a nota final" que a pessoa obteve, respondendo a determinadas tarefas (conjunto de itens). O modelo da Psicometria moderna (TRI) se interessa pelo desempenho em cada uma das tarefas ou itens, portanto, para a TRI, é importante saber a probabilidade de uma pessoa em acertar determinado item e os fatores que influenciam cada item do teste. Essas diferenças, na forma de avaliação das respostas, identificam preocupações também diferentes na construção dos instrumentos de avaliação. A TCT mostra interesse na qualidade de um teste (conjunto de itens), enquanto a TRI procura a qualidade dos itens que irão compor o instrumento ${ }^{73,74}$. A TRI se baseia no modelo dos traços latentes que são características do indivíduo, por exemplo, aptidões ou habilidades, cuja observação se dá de forma indireta. Esse tipo de variável deve ser inferido a partir da observação de um conjunto de fatores, ou traços latentes (variáveis secundárias), que esteja relacionada a ela. 
A TRI foi a escolhida para o estudo, pois emprega formas de representar a relação entre a probabilidade de um indivíduo dar uma certa resposta a um item e seus traços latentes, proficiências ou habilidades na área de conhecimento a serem avaliadas $^{73,74}$. A TRI modela a probabilidade de o aluno dar uma resposta correta ao item em função da sua proficiência. Quanto maior a proficiência, maior a probabilidade de o aluno acertar o item.

Na TRI, a natureza de um item pode ser dicotômica ou não dicotômica. Itens tipo múltipla escolha ou itens abertos (de resposta livre) podem ser avaliados de forma dicotomizada, quando corrigidos como certo ou errado. Os itens abertos (de resposta livre) ou os itens tipo múltipla escolha avaliados de forma graduada, isto é, itens que são elaborados ou corrigidos de modo a ter-se uma ou mais categorias intermediárias, ordenadas entre as categorias certo ou errado, são denominados itens não dicotômicos. Na prática, os modelos logísticos para itens dicotômicos são os modelos de resposta ao item mais utilizados ${ }^{74}$. 


\section{MÉTODOS}




\section{MÉTODOS}

Este estudo metodológico, de análise secundária de dados, foi desenvolvido em três etapas. A primeira etapa compreendeu o preparo dos dados primários, a segunda etapa, a criação e interpretação da escala de proficiência em raciocínio diagnóstico e a terceira etapa foi a análise das proficiências dos estudantes do curso de graduação em enfermagem e dos enfermeiros que participaram do estudo primário.

\subsection{PREPARO DOS DADOS PRIMÁRIOS}

\subsubsection{Materiais}

O banco de itens desenvolvido neste estudo foi baseado no conjunto de itens proposto para o Diagnostic Reasoning Test (DRT) criado por Gordon e Plunkett ${ }^{\mathrm{i}}$. Essas autoras criaram 35 itens baseados na teoria de geração de hipóteses com a finalidade de avaliar o raciocínio diagnóstico.

O modelo do processamento de informações (modelo analítico do processo diagnóstico ${ }^{10}$ ) serviu de base conceitual para a construção dos itens, que se referem a diagnósticos de enfermagem freqüentemente encontrados, conforme a literatura e conforme as investigações prévias das autoras dos itens.

A estrutura básica dos itens do DRT é a de um teste escrito, composto por três partes em que o respondente deve ler um pequeno texto que apresenta alguns dados sobre um paciente e, com base nesses dados, precisa listar os possíveis diagnósticos de enfermagem (hipóteses). A idéia é analisar as hipóteses diagnósticas ativadas pelos dados apresentados. Na seqüência, o respondente deve enunciar qual hipótese, entre as indicadas, é a mais provável e que outros dados ele necessitaria para

\footnotetext{
${ }^{\text {i }}$ Gordon M, Plunkett E. Psychometric properties of a diagnostic reasoning instrument [resumo do projeto sobre avaliação do raciocínio diagnóstico de enfermeiras]. Boston, 1999
} 
confirmá-la. A Quadro 1 mostra um exemplo da estrutura de um item do DRT de Gordon e Plunkett (1999):

Quadro 1 - Item do Diagnostic Reasoning Test (DRT)

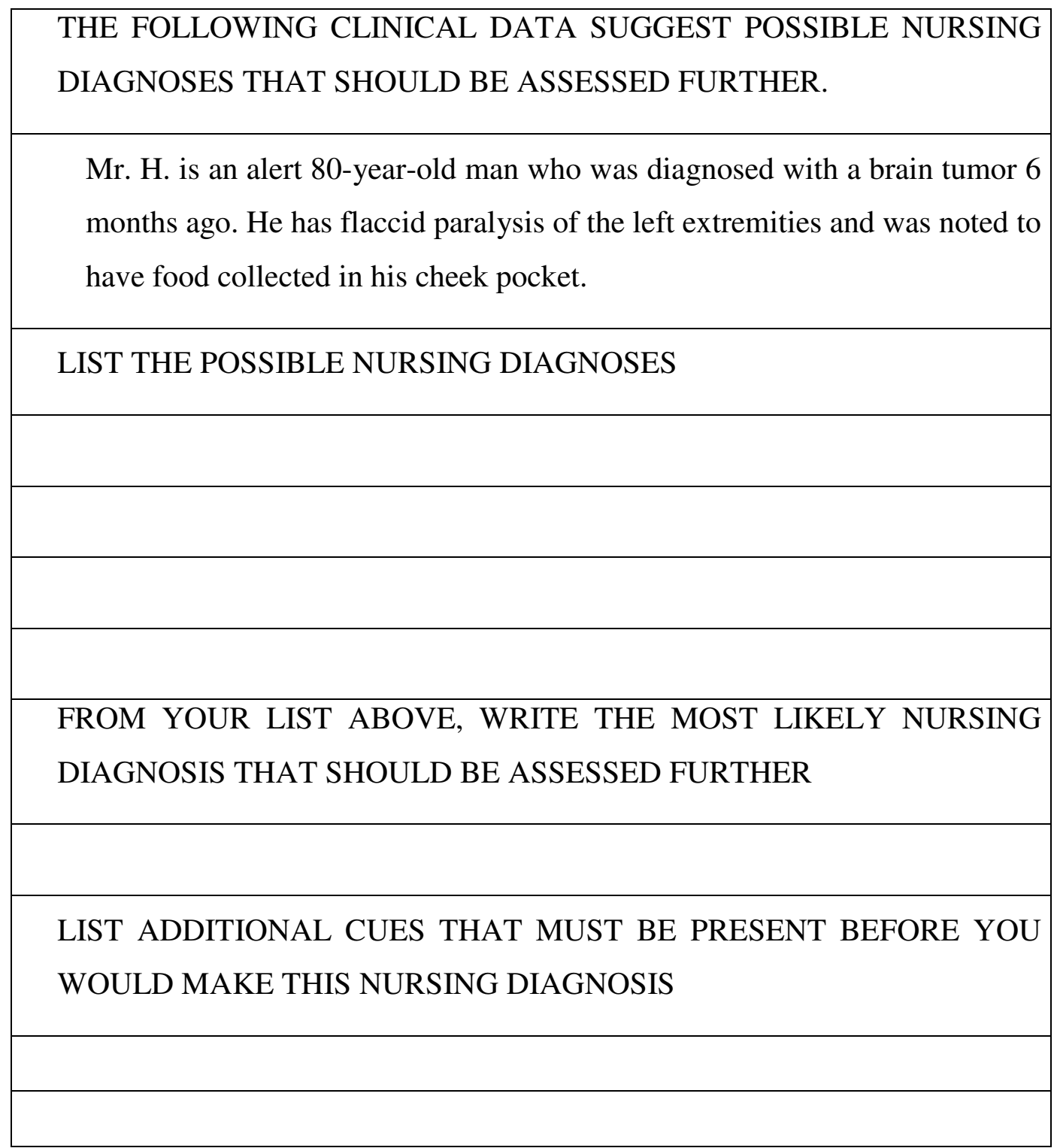

As autoras construíram 35 itens de acordo com a estrutura apresentada no Quadro 1 e os distribuíram em sete formulários, contendo 10 itens cada um. Dos 35 itens, 48,6\% são compostos por situações que envolvem pessoas adultas do sexo masculino, 34,3\%, por mulheres adultas, $8,6 \%$, por adolescentes, $5,7 \%$, por crianças e 2,8\%, por bebês. A idade dos homens variou entre 22 e 82 anos, com uma média de 52,6 anos, sendo que, em um caso, não houve menção da idade. As mulheres tinham idades entre 19 e 80 anos, com uma média de 41,5 anos, sendo que, em um caso, não 
houve menção da idade. Os 35 itens não estão apresentados neste relatório, para a garantia de seu uso fidedigno posteriormente.

Ao compararmos a estrutura do item com os quatro componentes do processo de geração de hipóteses relatados por Elstein et al. ${ }^{4}$, podemos reconhecer todos os componentes que envolvem o processo de hipotetizar. Na primeira parte do item, é necessário que o respondente identifique as pistas disponíveis, para que os elementos problemáticos sejam identificados. Ativando a memória de longa duração, padrões serão reconhecidos e hipóteses serão geradas. Na segunda parte, as hipóteses levantadas são ordenadas de acordo com a estimativa subjetiva do sujeito e, na terceira parte, o respondente deve pesquisar pistas adicionais, para que as hipóteses levantadas sejam confirmadas ou descartadas.

Com autorização das autoras do DRT, os 35 itens foram adaptados para a língua portuguesa ${ }^{\mathrm{ii}}$ e o conjunto foi denominado Teste de Raciocínio Diagnóstico (TRD). O sistema de codificação proposto pelas autoras, contendo as possibilidades de respostas à primeira parte dos itens, também foi adaptado. No estudo primário os sete instrumentos finais foram então aplicados a 362 enfermeiras e estudantes de graduação em enfermagem, de instituições nos estados do Paraná, São Paulo, Rio de Janeiro e Minas Gerais ${ }^{\mathrm{ii}}$.

\subsubsection{Amostra}

A amostra do presente estudo foram as respostas do estudo brasileiro ${ }^{\mathrm{ii}}$ e na Tabela 1 estão apresentadas as suas características.

\footnotetext{
${ }^{i i}$ Cruz DALM. Adaptação e validação de instrumentos relacionados ao raciocínio clínico [relatório de pesquisa]. São Paulo, EEUSP/FAPESP; 2002.
} 
Tabela 1 - Características da amostra de respondentes do TRD segundo sexo, idade e categoria, São Paulo - 2002

\begin{tabular}{lc}
\hline \multicolumn{1}{c|}{ Características } & Freqüência (\%) \\
\hline Sexo & $338(93,4)$ \\
Feminino & $24(6,6)$ \\
Masculino & \\
Idade (anos) & $29,5(9,4)$ \\
Média (DP) & 18 \\
Mínima & 64 \\
Máxima & \\
Categoria & $142(39,2)$ \\
Enfermeira & $212(58,6)$ \\
Estudante de graduação & $8(2,2)$ \\
Sem informação & \\
\hline
\end{tabular}

\subsubsection{Procedimentos}

Os procedimentos realizados para preparar os dados primários para este estudo foram a revisão e construção dos gabaritos para as três partes do item (partes A, B e C), estabelecimento de critérios para a aplicação desses gabaritos, aplicação do gabarito e o preparo de dois bancos de dados.

\section{$\underline{\text { Revisão e construção dos gabaritos }}$}

Cada item do DRT envolve três partes em sua resposta. Somente a parte A possuía gabarito, porém havia sido elaborado com base em edição antiga da classificação da North American Nursing Diagnosis Association - International ${ }^{75}$ (NANDA-I). Portanto, foi realizada a revisão do gabarito dessa primeira parte e a construção dos gabaritos para as partes B e C, baseados em edição mais recente da classificação dos diagnósticos de enfermagem, proposta pela NANDA-I ${ }^{75}$.

\section{Critérios para aplicação dos gabaritos}

Pelo fato de o gabarito ter sido elaborado com base nos diagnósticos de enfermagem da taxonomia II da NANDA-I ${ }^{75}$ e não se ter exigido que o respondente 
tivesse afinidade com a linguagem diagnóstica para ser participante do estudo, muitas respostas não estavam exatamente conforme a terminologia utilizada pela NANDA-I ${ }^{75}$. Portanto, para a correção, foram estabelecidos critérios de julgamento, pelos quais as respostas foram consideradas corretas quando:

1) O respondente escreveu o conceito diagnóstico conforme o gabarito ou;

2) O respondente escreveu uma frase ou expressão que indicasse o conceito diagnóstico correto ou;

3) O respondente escreveu uma frase ou expressão que mencionasse o conceito diagnóstico correto.

Do mesmo modo, estabeleceram-se critérios para respostas erradas. Foram consideradas respostas erradas aquelas:

1) cujo significado foi diferente do gabarito;

2) deixadas em branco;

3) cuja caligrafia não foi legível;

4) com frases consideradas sem sentido ou duvidosas.

À medida que os itens eram corrigidos, o gabarito do item correspondente também era analisado, a fim de se observar se as respostas dadas pelos respondentes, e que não constavam da listagem de respostas corretas, poderiam ser incluídas como corretas. No caso de algum diagnóstico ter sido incorporado na lista do gabarito, todos os itens que já haviam sido corrigidos, eram novamente analisados.

\section{Aplicação dos gabaritos}

Os gabaritos atualizados e seus critérios foram aplicados aos questionários da amostra do estudo primário $(n=362)$, atribuindo-se escores às respostas. A variação dos escores foi diferente para cada parte do item. A parte A do item poderia ter escore máximo de 4 . O respondente podia ter até 4 de suas hipóteses diagnósticas levantadas consideradas corretas. Caso o respondente descrevesse mais de quatro hipóteses diagnósticas, todas eram lidas e somente as corretas eram consideradas. $\mathrm{Na}$ parte B do item, a pessoa deveria escolher apenas uma das hipóteses diagnósticas levantadas como a mais provável. Caso o respondente escrevesse mais de uma hipótese diagnóstica, todas eram lidas e, se a mais provável estivesse entre as 
respostas, ele receberia o escore máximo, porém se a resposta não mostrasse a hipótese diagnóstica mais provável correta, o escore seria zero. Para a parte $\mathrm{C}$ do item o respondente deveria citar no máximo dois dados, portanto, o escore variou de 0 a 2.

\section{$\underline{\text { Preparo dos bancos de dados }}$}

Foram preparados dois bancos de dados em programa Excel 2003, de acordo com os gabaritos revisados. Em um primeiro banco foram lançados os dados de caracterização de cada respondente e os escores obtidos nas partes A, B e C e o escore total do item, correspondente à soma dos escores nas três partes. De cada respondente foram lançadas as variáveis sexo, idade, categoria (enfermeira ou estudante de graduação), tempo de profissão (no caso das enfermeiras) ou semestre de graduação (no caso de estudante de graduação) e mais cinco variáveis relacionadas ao grau de contato com o diagnóstico de enfermagem.

O segundo banco foi composto pelos dados de caracterização dos respondentes e pelos escores totais dicotomizados. No processo de dicotomização das respostas, a parte $\mathrm{C}$ do item foi excluída pela dificuldade na interpretação das respostas em certo ou errado levando-se em consideração todas as três partes do item.

Os principais modelos da TRI são aplicáveis a itens com respostas dicotômicas e instrumentos compostos por apenas um traço latente (denominados unidimensionais), ou seja, a resposta dada a cada item deve ser dicotomizada como categoria correta, se o indivíduo respondeu corretamente ao item, ou incorreta, em caso contrário ${ }^{76}$. O processo de estimação dos parâmetros do modelo exige a suposição de independência local ou independência condicional, isto é, pressupõe-se que para uma dada habilidade as respostas aos diferentes itens que compõem o teste sejam independentes, isto é, a resposta a um item não influencia a de outro item ${ }^{74}$. Assim, as possíveis combinações dos escores das partes A e B foram primeiramente codificadas em 10 categorias de respostas, considerando-se a quantidade de acertos na parte A e se houve acerto ou não na parte B (Quadro 2): 
Quadro 2 - Categorias possíveis de respostas segundo o número de acertos nas partes A e B dos itens

\begin{tabular}{|c|c|c|}
\hline $\begin{array}{c}\text { Número de acertos na } \\
\text { parte A do item }\end{array}$ & $\begin{array}{l}\text { Número de acertos na } \\
\text { parte } \mathrm{B} \text { do item }\end{array}$ & Categorias de Respostas \\
\hline 0 & 0 & 1 \\
\hline 0 & 1 & 2 \\
\hline 1 & 0 & 3 \\
\hline 2 & 0 & 4 \\
\hline 3 & 0 & 5 \\
\hline 4 & 0 & 6 \\
\hline 1 & 1 & 7 \\
\hline 2 & 1 & 8 \\
\hline 3 & 1 & 9 \\
\hline 4 & 1 & 10 \\
\hline
\end{tabular}

Após esse procedimento, foi realizada uma combinação dessas 10 categorias de respostas, de forma a reduzi-las para 4 categorias (Quadro 3):

Quadro 3 - Redução das 10 categorias de respostas para 4 categorias

\begin{tabular}{|c|c|}
\hline $\begin{array}{c}\text { Combinação das } 10 \text { categorias de } \\
\text { respostas }\end{array}$ & 4 categorias de respostas \\
\hline 1,2 e 3 & 0 \\
\hline 4,5 e 6 & 1 \\
\hline 7 & 3 \\
\hline 8,9 e 10 & 3 \\
\hline
\end{tabular}

Para finalizar a dicotomização dos escores, transformamos as 4 categorias de respostas em duas (Quadro 4): 
Quadro 4 - Redução de 4 para 2 categorias de respostas

\begin{tabular}{|c|c|}
\hline $\begin{array}{c}\text { Combinação das 4 } \\
\text { categorias de respostas }\end{array}$ & Padrão dicotomizado \\
\hline 0 e 1 & 0 \\
\hline 2 e 3 & 1 \\
\hline
\end{tabular}

Observa-se que o padrão dicotomizado acabou considerando as respostas da parte B dos itens como a definidora de erro ou acerto. Em síntese, acertaram o item, todos que indicaram e acertaram a hipótese mais provável (parte $\mathrm{B}$ do item). Com esse padrão, todas as possibilidades de acertos na parte A associada a erro na parte B foram consideradas erradas. A dicotomização, portanto, limitou a diversidade de informações que, originalmente, o item permitiria. Esse procedimento foi exigência do modelo disponível para a análise dos dados.

\subsection{CRIAÇÃO E INTERPRETAÇÃO DA ESCALA}

A criação e a interpretação da escala de proficiência em raciocínio diagnóstico foram baseadas no banco de dados com os escores dicotomizados e a análise dos itens foi o primeiro procedimento. A análise foi feita pelo programa BILOG que é uma ferramenta computacional específica de itens dicotômicos ou dicotomizados para modelos unidimensionais de 1,2 e 3 parâmetros $^{74}$.

\subsubsection{Análise dos itens}

Os modelos logísticos de 1, 2 e 3 parâmetros são os mais utilizados na prática para a avaliação da relação da probabilidade de acerto de um item com a aptidão que o teste deve medir ${ }^{73,74}$. Esses três modelos avaliam, respectivamente, a dificuldade do item, a dificuldade e a discriminação do item, e a dificuldade, discriminação e a resposta correta dada ao acaso, comumente conhecida como "chute",73,74. 
Neste estudo, o modelo indicado, entre os disponíveis, foi o modelo logístico unidimensional de dois parâmetros (ML2), pois se assumiu a existência de apenas um traço latente e a impossibilidade de acerto ao acaso. Esse modelo avalia os parâmetros de dificuldade e discriminação do item e a equação que os avalia foi descrita por Birnbaun em $1968^{73}$ :

$$
P_{i}(\theta)=\frac{e_{i}^{D_{i}(\theta-b)}}{1+e_{i}^{D_{i}(\theta-b)}}
$$

Onde:

$P_{i}(\theta)$ é a probabilidade do sujeito com aptidão $\theta$ responder o item i

$\theta$ é o traço latente

$\mathrm{a}_{\mathrm{i}}$ é o parâmetro de discriminação do item;

$b_{\mathrm{i}}$ é o parâmetro de dificuldade do item;

$e$ é um número com valor de $2,7182818 \ldots . .(=2,72)$

D é uma constante que vale 1,7

Valores do parâmetro $a$ muito baixos, menores que 0,75 , indicam itens pouco discriminativos e o valor do parâmetro $b$ indica o grau de habilidade que a pessoa deve possuir para acertar o item ${ }^{74}$.

Antes de se estimarem os parâmetros pela TRI, foram obtidos os coeficientes de correlação item-total e ponto bisserial de cada item. A correlação bisserial é utilizada na situação na qual as variáveis são contínuas e foram reduzidas a duas categorias (dicotomizadas) ${ }^{73}$. Para a correlação bisserial, os valores de corte assumidos foram os menores que $-0,15^{74}$. Coeficientes de correlação bisserial menores que $-0,15$ indicaram a exclusão do item antes das estimativas pela TRI $^{74}$.

Os itens que permaneceram depois da correlação bisserial tiveram seus parâmetros $a$ e $b$ - discriminação e dificuldade, respectivamente - estimados pelo modelo logístico unidimensional de dois parâmetros. 


\subsubsection{Criação e interpretação da escala de raciocínio diagnóstico}

Os parâmetros $a$ e $b$ de cada item serviram para calcular a probabilidade de acerto do item em cada nível de uma escala de proficiência em raciocínio diagnóstico. A escala de proficiência foi criada por meio da determinação de um número, escolhido sem nenhum critério, para ser o seu ponto médio e intervalos regulares acima e abaixo desse ponto médio, que indicam desvios padrão do ponto médio. O número escolhido para ponto médio foi 200 e os intervalos regulares, acima e abaixo do ponto médio, foram definidos em 20. Os valores assim definidos $(\ldots 160,180,200,220,240$...) indicaram níveis de proficiência em raciocínio diagnóstico. Com essa definição, uma pessoa com proficiência em raciocínio diagnóstico igual a 200 tem proficiência média nessa habilidade. Variações acima desse valor $(220,240,260$, etc.) mostram proficiências acima do ponto médio; variações abaixo de 200 (180, 160, 140, etc.) mostram proficiências baixas.

A criação da escala é fundamental, pois é ela que permite identificar o nível de proficiência do indivíduo, conforme sua posição na escala de medida. Pessoas com níveis de proficiência abaixo do valor médio, por exemplo, 180 ou 120, apresentaram desempenho em raciocínio diagnóstico inferior ao desempenho médio, porém com desvios-padrão variados. A pessoa que se localizou no nível 180 estava apenas a um desvio abaixo da média, enquanto que, a que se localizou no nível 120 , estava a quatro desvios abaixo da média, o que é um desempenho pior se comparado com o 180. O mesmo raciocínio aplica-se aos valores acima da média estabelecida.

Definidos os valores da escala, foi feita a calibração dos itens. Calibrar os itens significa identificar, na escala criada, qual nível de proficiência cada item melhor representa. Para fazer a calibração, os parâmetros dos itens (dificuldade e discriminação), obtidos pela TRI, foram usados para calcular as probabilidades de acertá-los em cada nível da escala. Isto é, calculou-se a probabilidade que qualquer pessoa com certo nível de proficiência, por exemplo, igual a 180, tem para acertar cada um dos itens. Isso foi feito para todos os itens em todos os níveis de proficiência. Expresso de outra forma: com a escala definida e os parâmetros $a$ e $b$ estimados para cada item, foram calculadas as probabilidades de acerto de cada item para cada nível de proficiência. 
Para o cálculo desses valores, os valores de " $a$ " $e$ " $b$ " foram transformados $\left(a_{t}\right.$ $e b_{t}$ ) para a eliminação de valores negativos, da seguinte forma ${ }^{74}$ :

$$
\begin{aligned}
& \text { - } \mathrm{a}_{\mathrm{t}}=\frac{-\mathrm{a}}{\text { desvio padrão }} \\
& \text { - } \mathrm{b}_{\mathrm{t}}=(\text { desvio padrão x } \quad \mathrm{b})+200
\end{aligned}
$$

Definiu-se o nível de proficiência de cada item como aquele em que a probabilidade de acerto foi mais próxima de $65 \%^{74}$.

A interpretação da escala foi outro procedimento envolvido nessa fase do estudo. Interpretar a escala significa descrever o melhor possível as habilidades, aptidões ou conhecimentos que a pessoa deve possuir em cada nível de proficiência da escala. As descrições dos níveis de proficiência são orientadas pela análise qualitativa dos conteúdos dos itens que são típicos de cada nível. Um item é típico de um nível se $\mathrm{se}^{74}$ :

1) A probabilidade de acerto no nível de proficiência for maior que $65 \%$;

2) A probabilidade de acerto do item no nível de proficiência imediatamente anterior for menor que $50 \%$;

3) A diferença entre a probabilidade de acerto no nível potencialmente típico e a probabilidade acerto no nível imediatamente anterior é maior que 30\%.

Neste estudo, definiu-se como itens típicos de um nível aqueles que mais se aproximaram do atendimento dos três critérios.

Para interpretar a escala de raciocínio diagnóstico, os itens típicos de cada nível foram analisados qualitativamente. Diversos aspectos foram considerados nessa análise: características demográficas dos pacientes descritos nos itens, ambiente em que a situação descrita se passa, quantidade de dados apresentados, características das hipóteses diagnósticas prováveis, por exemplo. Com base nessa análise qualitativa dos itens típicos, foram feitas descrições para interpretar cada nível da escala de proficiência em raciocínio diagnóstico. 


\subsection{ANÁLISE DA PROFICIÊNCIA EM RACIOCÍNIO DIAGNÓSTICO}

A proficiência dos participantes do estudo primário foi gerada a partir dos valores da escala criada, na qual o ponto médio foi igual a 200 com intervalos de 20 desvios-padrão.

Cada sujeito foi ligado ao nível de proficiência requerido nos itens que acertaram e as proficiências foram estimadas pelo método bayesiano EAP (Expected a Posteriori) considerando os parâmetros fixos dos itens e a suposição de independência entre as habilidades de diferentes indivíduos ${ }^{74}$.

A proficiência em raciocínio diagnóstico dos participantes foi testada quanto à associação com variáveis selecionadas. Foi aplicado o teste $t$-student para associação com a categoria do participante (enfermeira ou estudante). Coeficientes de correlação de Pearson foram estimados para testar as associações da proficiência com o tempo de experiência como enfermeira, com o tempo no curso de graduação para os estudantes e com o grau de contato com o diagnóstico de enfermagem. Assumiu-se para todos os testes o nível de significância de 0,05.

O grau de contato com o diagnóstico de enfermagem foi avaliado por meio de cinco atividades (participação em pesquisa; uso na prática clínica; participação em eventos; participação em aulas; leitura), nas quais o respondente indicava com que frequiência a atividade era realizada (nada; quase nada; pouco; muito), conforme proposto por Oliva et al. ${ }^{77}$. As respostas nas atividades selecionadas receberam escores de 1 a 4: 1 para resposta "nada"; 2 para resposta "quase nada"; 3 para resposta "pouco" e 4 para resposta "muito". Para a análise das respostas foram calculadas as médias simples em cada atividade e a média geral de contato. 
RESULTADOS 


\section{RESULTADOS}

Inicialmente, serão apresentados os resultados de criação e interpretação da escala de proficiência em raciocínio diagnóstico e, a seguir, os resultados das análises de associação entre proficiência em raciocínio diagnóstico e variáveis selecionadas.

\subsection{CRIAÇÃO E INTERPRETAÇÃO DA ESCALA DE PROFICIÊNCIA EM RACIOCÍNIO DIAGNÓSTICO}

A Tabela 2 mostra os resultados da correlação bisserial. Conforme apresentado no capítulo de métodos, um dos critérios para a manutenção de um item era que a correlação bisserial não fosse menor que $-0,15$.

Tabela 2 - Análise descritiva dos itens e valores da correlação bisserial, São Paulo 2007

\begin{tabular}{c|c|c|c|c}
\hline \multirow{2}{*}{ Item } & \multirow{2}{*}{$\mathrm{N}$} & \multicolumn{2}{|c|}{ Respostas Corretas } & Correlação \\
\cline { 3 - 4 } & & $\mathrm{n}$ & $\%$ & \\
\hline 1 & 86 & 7,0 & 8,1 & $-0,087$ \\
2 & 86 & 22,0 & 25,6 & $-0,127$ \\
3 & 86 & 10,0 & 11,6 & $-0,413$ \\
4 & 86 & - & - & 0,000 \\
5 & 86 & 30,0 & 34,9 & 0,081 \\
6 & 111 & 10,0 & 9,0 & 0,364 \\
7 & 111 & 72,0 & 64,9 & 0,435 \\
8 & 111 & 15,0 & 13,5 & 0,237 \\
9 & 111 & 35,0 & 31,5 & 0,045 \\
10 & 111 & 6,0 & 5,4 & 0,091 \\
11 & 120 & 24,0 & 20,0 & $-0,130$ \\
12 & 120 & 7,0 & 5,8 & 0,058
\end{tabular}

continua 
conclusão

\begin{tabular}{|c|c|c|c|c|}
\hline \multirow{2}{*}{ Item } & \multirow{2}{*}{$\mathrm{N}$} & \multicolumn{2}{|c|}{ Respostas Corretas } & \multirow{2}{*}{$\begin{array}{c}\text { Correlação } \\
\text { Bisserial }\end{array}$} \\
\hline & & $\mathrm{n}$ & $\%$ & \\
\hline 13 & 120 & 2,0 & 1,7 & 0,412 \\
\hline 14 & 120 & 11,0 & 9,2 & 0,396 \\
\hline 15 & 120 & 21,0 & 17,5 & $-0,142$ \\
\hline 16 & 105 & 10,0 & 9,5 & 0,394 \\
\hline 17 & 105 & 28,0 & 26,7 & 0,250 \\
\hline 18 & 105 & 3,0 & 2,9 & 0,046 \\
\hline 19 & 105 & 16,0 & 15,2 & 0,250 \\
\hline 20 & 105 & 5,0 & 4,8 & 0,256 \\
\hline 21 & 105 & 31,0 & 29,5 & 0,034 \\
\hline 22 & 105 & 21,0 & 20,0 & 0,376 \\
\hline 23 & 105 & 3,0 & 2,9 & 0,291 \\
\hline 24 & 105 & 31,0 & 29,5 & 0,255 \\
\hline 25 & 105 & 23,0 & 21,9 & 0,175 \\
\hline 26 & 111 & 1,0 & 0,9 & 0,116 \\
\hline 27 & 111 & 18,0 & 16,2 & 0,162 \\
\hline 28 & 111 & 7,0 & 6,3 & $-0,155$ \\
\hline 29 & 111 & 22,0 & 19,8 & 0,174 \\
\hline 30 & 111 & 13,0 & 11,7 & 0,303 \\
\hline 31 & 86 & 6,0 & 7,0 & 0,126 \\
\hline 32 & 86 & 1,0 & 1,2 & $-0,216$ \\
\hline 33 & 86 & 30,0 & 34,9 & 0,121 \\
\hline 34 & 86 & 10,0 & 29,5 & 0,034 \\
\hline 35 & 86 & 26,0 & 20,0 & 0,376 \\
\hline
\end{tabular}

Observa-se que não houve nenhuma resposta correta no item 4, entre os 86 respondentes. Esse item foi excluído da seleção, pois a ausência de acerto significa que não há informação para que o item seja analisado. Os itens 3, 28 e 32 apresentaram correlação bisserial menor que $-0,15$ (Tabela 2), sendo excluídos das análises subseqüentes pela TRI ${ }^{74}$. A Tabela 3 mostra os resultados dos parâmetros "a" e "b" obtidos da análise pela TRI" 
Tabela 3 - Estimativa dos parâmetros dos itens pela TRI, São Paulo - 2007

\begin{tabular}{c|c|c}
\hline Item & Valor “a” & Valor "b" \\
\hline 1 & 0.692 & 3.879 \\
2 & 0.543 & 2.191 \\
5 & 0.784 & 0.970 \\
6 & 1.128 & 2.448 \\
7 & 1.359 & -0.631 \\
8 & 0.797 & 2.584 \\
9 & 0.666 & 1.259 \\
10 & 0.767 & 4.047 \\
11 & 0.559 & 2.545 \\
12 & 0.860 & 3.496 \\
13 & 1.202 & 3.841 \\
14 & 1.189 & 2.259 \\
15 & 0.526 & 3.019 \\
16 & 1.043 & 2.447 \\
17 & 0.834 & 1.303 \\
18 & 0.872 & 4.346 \\
19 & 1.038 & 1.881 \\
20 & 0.980 & 3.378 \\
21 & 0.578 & 1.555 \\
22 & 1.189 & 1.400 \\
23 & 1.052 & 3.750 \\
24 & 0.856 & 1.111 \\
25 & 0.777 & 1.772 \\
26 & 0.894 & 5.736 \\
27 & 0.814 & 2.327 \\
29 & 0.868 & 1.897 \\
30 & 1.164 & 2.183 \\
31 & 0.907 & 3.410 \\
33 & 0.805 & 1.045 \\
34 & 1.080 & 2.437 \\
& 1.292 & 1.030 \\
\hline & &
\end{tabular}


Conforme apresentado no método, os valores do parâmetro "a" muito baixos, menores que 0,75 , indicam itens pouco discriminativos e o valor do parâmetro "b" indica o nível de capacidade que a pessoa deve possuir para acertar o item. Esses valores foram aplicados para calibrar os itens segundo graus de proficiência.

A Tabela 4 apresenta a escala criada e o posicionamento dos itens, segundo os níveis de proficiência na escala. Conforme descrito no método, o valor médio da escala de proficiência em raciocínio diagnóstico foi definido em 200, com intervalos de 20 desvios padrão. Os valores de cada item indicam qual a probabilidade que um indivíduo com determinado nível de proficiência tem para acertar o item e isso é feito para cada nível da escala.

Definiu-se o nível de proficiência de cada item como aquele em que a probabilidade de acerto foi mais próxima de $65 \%$.

Os valores obtidos (Tabela 4) orientaram: 1) a definição do nível de proficiência de cada item (nível em que a probabilidade de acerto foi mais próxima de $65 \%$ ) e 2) a escolha dos itens que foram usados para descrever os níveis da escala, chamados itens âncora, ou itens típicos de cada nível (probabilidade maior que 65\%; o valor da probabilidade do nível de proficiência anterior deve ser abaixo de 50\%; a diferença entre esses dois valores deve ser maior que 30\%). Na Tabela 4 estão destacados, para cada item, os pontos mais próximos de 0,65 e os imediatamente abaixo, para que o leitor possa observar a aplicação dos critérios para determinar os níveis de proficiência dos itens e os itens típicos de cada nível. 
Tabela 4 - Posicionamento dos itens segundo os níveis de proficiência na escala, São Paulo - 2007

\begin{tabular}{|c|c|c|c|c|c|c|c|c|c|c|c|c|c|c|}
\hline \multirow{2}{*}{ Item } & \multirow{2}{*}{$a_{t}$} & \multirow{2}{*}{$b_{t}$} & \multicolumn{12}{|c|}{ Escala (Nível de Proficiência) } \\
\hline & & & 120 & 140 & 160 & 180 & 200 & 220 & 240 & 260 & 280 & 300 & 320 & 340 \\
\hline 1 & 0,035 & 277,58 & 0,00 & 0,01 & 0,02 & 0,03 & 0,06 & 0,12 & 0,21 & 0,35 & 0,52 & 0,68 & 0,81 & 0,90 \\
\hline 2 & 0,027 & 243,82 & 0,03 & 0,06 & 0,09 & 0,15 & 0,23 & 0,34 & 0,47 & 0,61 & 0,73 & 0,82 & 0,89 & 0,93 \\
\hline 5 & 0,039 & 219,40 & 0,02 & 0,04 & 0,09 & 0,18 & 0,32 & 0,51 & 0,69 & 0,83 & 0,91 & 0,96 & 0,98 & 0,99 \\
\hline 6 & 0,056 & 248,96 & 0,00 & 0,00 & 0,01 & 0,02 & 0,06 & 0,16 & 0,38 & 0,65 & 0,85 & 0,95 & 0,98 & 0,99 \\
\hline 7 & 0,068 & 187,38 & 0,01 & 0,04 & 0,13 & 0,38 & 0,70 & 0,90 & 0,97 & 0,99 & 1,00 & 1,00 & 1,00 & 1,00 \\
\hline 8 & 0,040 & 251,68 & 0,01 & 0,01 & 0,03 & 0,05 & 0,11 & 0,22 & 0,39 & 0,58 & 0,76 & 0,87 & 0,94 & 0,97 \\
\hline 9 & 0,033 & 225,18 & 0,03 & 0,06 & 0,10 & 0,18 & 0,30 & 0,46 & 0,62 & 0,76 & 0,86 & 0,92 & 0,96 & 0,98 \\
\hline 10 & 0,038 & 280,94 & 0,00 & 0,00 & 0,01 & 0,02 & 0,04 & 0,09 & 0,17 & 0,31 & 0,49 & 0,68 & 0,82 & 0,91 \\
\hline 11 & 0,028 & 250,90 & 0,03 & 0,04 & 0,07 & 0,12 & 0,19 & 0,30 & 0,42 & 0,56 & 0,69 & 0,80 & 0,87 & 0,92 \\
\hline 12 & 0,043 & 269,92 & 0,00 & 0,00 & 0,01 & 0,02 & 0,05 & 0,10 & 0,22 & 0,39 & 0,61 & 0,78 & 0,90 & 0,95 \\
\hline 13 & 0,060 & 276,82 & 0,00 & 0,00 & 0,00 & 0,00 & 0,01 & 0,03 & 0,10 & 0,27 & 0,55 & 0,80 & 0,93 & 0,98 \\
\hline 14 & 0,059 & 245,18 & 0,00 & 0,00 & 0,01 & 0,02 & 0,06 & 0,18 & 0,42 & 0,71 & 0,89 & 0,96 & 0,99 & 1,00 \\
\hline 15 & 0,026 & 260,38 & 0,02 & 0,04 & 0,07 & 0,11 & 0,17 & 0,26 & 0,37 & 0,50 & 0,63 & 0,74 & 0,83 & 0,89 \\
\hline 16 & 0,052 & 248,94 & 0,00 & 0,00 & 0,01 & 0,03 & 0,07 & 0,18 & 0,39 & 0,64 & 0,83 & 0,93 & 0,98 & 0,99 \\
\hline 17 & 0,042 & 226,06 & 0,01 & 0,03 & 0,06 & 0,13 & 0,25 & 0,44 & 0,64 & 0,80 & 0,90 & 0,96 & 0,98 & 0,99 \\
\hline 18 & 0,044 & 286,92 & 0,00 & 0,00 & 0,00 & 0,01 & 0,02 & 0,05 & 0,11 & 0,24 & 0,43 & 0,64 & 0,81 & 0,91 \\
\hline 19 & 0,052 & 237,62 & 0,00 & 0,01 & 0,02 & 0,05 & 0,12 & 0,29 & 0,53 & 0,76 & 0,90 & 0,96 & 0,99 & 1,00 \\
\hline 20 & 0,049 & 267,56 & 0,00 & 0,00 & 0,01 & 0,01 & 0,04 & 0,09 & 0,21 & 0,41 & 0,65 & 0,83 & 0,93 & 0,97 \\
\hline 21 & 0,029 & 231,10 & 0,04 & 0,07 & 0,11 & 0,19 & 0,29 & 0,42 & 0,56 & 0,70 & 0,80 & 0,88 & 0,93 & 0,96 \\
\hline 22 & 0,059 & 228,00 & 0,00 & 0,01 & 0,02 & 0,05 & 0,16 & 0,38 & 0,67 & 0,87 & 0,96 & 0,99 & 1,00 & 1,00 \\
\hline 23 & 0,053 & 275,00 & 0,00 & 0,00 & 0,00 & 0,01 & 0,02 & 0,05 & 0,14 & 0,31 & 0,57 & 0,79 & 0,91 & 0,97 \\
\hline 24 & 0,043 & 222,22 & 0,01 & 0,03 & 0,07 & 0,14 & 0,28 & 0,48 & 0,68 & 0,83 & 0,92 & 0,97 & 0,99 & 0,99 \\
\hline 25 & 0,039 & 235,44 & 0,01 & 0,02 & 0,05 & 0,10 & 0,20 & 0,35 & 0,54 & 0,72 & 0,85 & 0,92 & 0,96 & 0,98 \\
\hline 26 & 0,045 & 314,72 & 0,00 & 0,00 & 0,00 & 0,00 & 0,01 & 0,01 & 0,03 & 0,08 & 0,17 & 0,34 & 0,56 & 0,76 \\
\hline 27 & 0,041 & 246,54 & 0,01 & 0,01 & 0,03 & 0,06 & 0,13 & 0,25 & 0,43 & 0,63 & 0,80 & 0,90 & 0,95 & 0,98 \\
\hline 29 & 0,043 & 237,94 & 0,01 & 0,01 & 0,03 & 0,07 & 0,16 & 0,31 & 0,52 & 0,72 & 0,86 & 0,94 & 0,97 & 0,99 \\
\hline 30 & 0,058 & 243,66 & 0,00 & 0,00 & 0,01 & 0,02 & 0,07 & 0,20 & 0,45 & 0,72 & 0,89 & 0,96 & 0,99 & 1,00 \\
\hline 31 & 0,045 & 268,20 & 0,00 & 0,00 & 0,01 & 0,02 & 0,04 & 0,10 & 0,22 & 0,41 & 0,63 & 0,81 & 0,91 & 0,96 \\
\hline 33 & 0,040 & 220,90 & 0,02 & 0,04 & 0,08 & 0,16 & 0,30 & 0,49 & 0,68 & 0,83 & 0,92 & 0,96 & 0,98 & 0,99 \\
\hline 34 & 0,054 & 248,74 & 0,00 & 0,00 & 0,01 & 0,02 & 0,07 & 0,17 & 0,38 & 0,65 & 0,84 & 0,94 & 0,98 & 0,99 \\
\hline 35 & 0,065 & 220,60 & 0,00 & 0,01 & 0,02 & 0,07 & 0,21 & 0,49 & 0,78 & 0,93 & 0,98 & 0,99 & 1,00 & 1,00 \\
\hline
\end{tabular}

Observa-se na Tabela 4 que não houve itens nos seguintes níveis: 220, 180, 160 e abaixo, 320 e acima de 340. O Quadro 5 mostra a distribuição dos itens segundo os níveis de proficiência. 
Quadro 5 - Distribuição dos itens segundo nível de proficiência, quantidade de itens em cada nível e número dos itens

\begin{tabular}{|c|c|c|}
\hline Nível de proficiência & $\begin{array}{c}\text { Quantidade de } \\
\text { Itens }\end{array}$ & Números dos itens \\
\hline 200 & 1 & 7 \\
\hline 240 & 7 & $2,6,14,16,19,21,25,27,29,30$ e \\
\hline 260 & 11 & $8,11,12,15,20$ e 31 \\
\hline 280 & 6 & $1,10,13,18$ e 23 \\
\hline 300 & 5 & 26 \\
\hline 340 & 1 & e 35 \\
\hline
\end{tabular}

\section{Interpretação da escala}

Aplicando-se os três critérios de avaliação do parâmetro do item identificamos os itens 'típicos' de cada nível de proficiência. Na Tabela 4 estão marcados em negrito os itens que mais se aproximaram dos três critérios estabelecidos (probabilidade maior que 65\%; o valor da probabilidade do nível de proficiência anterior deve ser abaixo de 50\%; a diferença entre esses dois valores deve ser maior que 30\%). Observa-se na Tabela 4 que os melhores itens para descrever os níveis de proficiência foram o 7 (200), o 22 (240), o 14 (260), o 20 (280), o 10 (300) e o $26(340)$.

Com a finalidade de buscar padrões que explicassem os níveis de proficiência, os itens típicos de cada nível foram extensivamente analisados. Primeiramente, quanto ao seu conteúdo e área clínica, depois, quanto aos diagnósticos de enfermagem mais freqüentemente levantados pelos respondentes, pelos diagnósticos de enfermagem considerados corretos, pela hipótese diagnóstica mais provável, pela frequiência dos escores da parte A do item e, finalmente, quanto aos domínios dos diagnósticos de enfermagem, segundo a taxonomia II da NANDAI $2005-2006^{75}$. O Quadro 6 apresenta os textos dos itens típicos de cada nível. 
Quadro 6 - Itens típicos dos níveis de proficiência em raciocínio diagnóstico

\begin{tabular}{|c|c|c|c|}
\hline $\begin{array}{l}\text { Número } \\
\text { do Item }\end{array}$ & Proficiência & Descrição do Item & Características \\
\hline 7 & 200 & $\begin{array}{l}\text { O Sr G., um trabalhador da } \\
\text { construção civil, casado, de } \\
40 \text { anos, é admitido para } \\
\text { cirurgia cardíaca amanhã. } \\
\text { Ele está inquieto com } \\
\text { frequiência cardíaca apical de } \\
98 \text { (linha basal 78). }\end{array}$ & $\begin{array}{c}9 \text { dados; } \\
\text { Contexto que não exige } \\
\text { conhecimento especializado; } \\
\text { Pistas problemáticas } \\
\text { convergentes e muito } \\
\text { específicas; } \\
\text { Papel tradicional da } \\
\text { enfermagem }\end{array}$ \\
\hline 22 & 240 & $\begin{array}{l}\text { O Sr. U. é um homem de } 45 \\
\text { anos, obeso, bancário, em } \\
\text { tração por pélvis fraturada, } \\
\text { que diz que simplesmente } \\
\text { não consegue usar a } \\
\text { comadre própria para } \\
\text { fraturas. }\end{array}$ & $\begin{array}{c}7 \text { dados; } \\
\text { Contexto que não exige } \\
\text { conhecimento especializado; } \\
\text { Pistas problemáticas } \\
\text { divergentes e pouco } \\
\text { específicas; } \\
\text { Papel tradicional da } \\
\text { enfermagem }\end{array}$ \\
\hline 14 & 260 & $\begin{array}{c}\text { O Sr. M é um assistente } \\
\text { social de } 25 \text { anos com } \\
\text { Síndrome da } \\
\text { Imunodeficiência Adquirida } \\
\text { e uma recente exposição à } \\
\text { influenza. Ele fala espanhol, } \\
\text { parece agitado e muito fraco. }\end{array}$ & $\begin{array}{c}8 \text { dados; } \\
\text { Contexto que não exige } \\
\text { conhecimento especializado; } \\
\text { Pistas problemáticas } \\
\text { divergentes e pouco } \\
\text { específicas; } \\
\text { Papel tradicional da } \\
\text { enfermagem }\end{array}$ \\
\hline 20 & 280 & $\begin{array}{c}\text { A Senhorita S, uma } \\
\text { estudante do ensino médio, } \\
\text { queixa-se de dor de } \\
\text { estômago e nervoso. Ela diz: } \\
\text { "Eu não esperava tanta } \\
\text { liberdade aqui. Eu tomei } \\
\text { algumas decisões erradas } \\
\text { que me deixam } \\
\text { desconfortável se vou a } \\
\text { minha igreja. }\end{array}$ & $\begin{array}{c}8 \text { dados; } \\
\text { Contexto que não exige } \\
\text { conhecimento especializado; } \\
\text { Pistas problemáticas } \\
\text { divergentes e pouco } \\
\text { específicas; } \\
\text { Papéis pouco tradicionais da } \\
\text { enfermagem }\end{array}$ \\
\hline
\end{tabular}

continua 
conclusão

\begin{tabular}{|c|c|c|c|}
\hline $\begin{array}{l}\text { Número } \\
\text { do Item }\end{array}$ & Proficiência & Descrição do Item & Características \\
\hline 10 & 300 & $\begin{array}{c}\text { O Sr J., um homem de } \\
\text { negócios aposentado de } 75 \\
\text { anos, queixa-se de jato fraco } \\
\text { de urina. Ele diz "todos os } \\
\text { dias são a mesma coisa aqui. } \\
\text { Levantar, comer, ir para a } \\
\text { cama". Ele cochila } \\
\text { freqüentemente durante o } \\
\text { dia. }\end{array}$ & $\begin{array}{c}6 \text { dados } \\
\text { Pistas problemáticas } \\
\text { divergentes e pouco } \\
\text { específicas; } \\
\text { Papéis pouco tradicionais da } \\
\text { enfermagem }\end{array}$ \\
\hline 26 & 340 & $\begin{array}{l}\text { O bebê Jones na Unidade } \\
\text { Neonatal de Cuidados } \\
\text { Intensivos nasceu } \\
\text { prematuramente com } 34 \\
\text { semanas e é pequeno para a } \\
\text { sua idade gestacional. }\end{array}$ & $\begin{array}{c}4 \text { dados; } \\
\text { Contexto de especialidade; } \\
\text { Pistas problemáticas } \\
\text { convergentes e inespecíficas; } \\
\text { Papéis pouco tradicionais da } \\
\text { enfermagem }\end{array}$ \\
\hline
\end{tabular}

Como resultado dessa análise, cinco critérios de discriminação foram levantados, a saber:

1) Especificidade das pistas problemáticas;

2) Convergência das pistas problemáticas;

3) Tipo de papel esperado da enfermagem evocado pela situação;

4) Grau de especialização de conhecimento envolvido na situação expressa no item;

5) Quantidade de dados oferecidos em cada item.

As pistas problemáticas foram definidas como os dados que podem desencadear hipóteses diagnósticas. Duas características das pistas problemáticas pareceram estar envolvidas na dificuldade dos itens. Uma foi a 'convergência', entendida como o grau com que as pistas problemáticas presentes apontam para uma mesma área de diagnósticos. A outra foi a 'especificidade', entendida como o grau com que a(s) pista(s) problemática(s) presente(s) é(são) específica(s) para uma 
determinada área de diagnósticos. Itens mais fáceis foram aqueles com pistas problemáticas mais convergentes e mais específicas.

O papel esperado da enfermagem evocado pelas situações descritas parece ser outro elemento na proficiência em raciocínio diagnóstico. Os itens que apresentam dados mais ligados ao papel tradicionalmente esperado no desempenho da enfermagem são aqueles que apresentam informações próximas ao que socialmente é visto como função própria da enfermagem, como por exemplo, controle de sinais vitais, preparo e administração de medicamentos, realização de curativos, cuidados com higienização e atenção a aspectos emocionais comuns na prática clínica como por exemplo ansiedade no pré-operatório. Os itens mais difíceis tratam de situações que não se limitam a esses papéis tradicionais como, por exemplo, situações em que são implicados preponderantemente problemas sociais ou emocionais mais complexos ou espirituais.

Um aspecto da situação expressa no item pareceu envolvido na dificuldade dos itens. Itens mais difíceis foram itens em que o contexto da situação de cuidado remetia a conhecimento especializado como o item do bebê em unidade neonatal.

Um dado foi definido como uma unidade de significado que permita compor a idéia da situação. A quantidade de dados apresenta alguma variação entre os itens, mas a diferença marcante está no item típico do nível 340 em que a quantidade dos dados, que nos outros varia de 6 a 9, nesse item é igual a 4. Dados relativos ao sexo, idade, profissão ou ocupação, diagnóstico médico ou algum procedimento realizado ou a ser realizado estão presentes em todos os itens.

Ao se avaliarem os itens típicos de cada nível quanto a esses critérios, observou-se um padrão relacionado ao nível de proficiência. $\mathrm{O}$ item locado no ponto médio da escala apresenta 9 dados e, quando comparados a níveis de proficiência mais altos, esse valor representa quase o número máximo de dados apresentados pelos itens típicos, porém um nível menor de inferência foi exigido no levantamento das hipóteses diagnósticas, essas sendo mais comuns à prática clínica da enfermeira, em situações cuja expectativa de desempenho está dentro do papel esperado tradicionalmente pela enfermagem. Já, os itens típicos locados entre os níveis 240 e 300, apresentaram variações na quantidade de dados, inferências mais complexas e hipóteses diagnósticas menos familiares em situações cujo desempenho se afastou do 
tradicionalmente esperado pela enfermagem. Para o nível 340, a quantidade de dados apresentou a maior variação, pistas pouco específicas em um contexto cujo cuidado exige conhecimento altamente especializado. O Quadro 7 resume estas avaliações.

Quadro 7 - Níveis de proficiência da escala segundo características dos itens típicos

\begin{tabular}{|c|c|c|c|c|c|c|c|c|}
\hline \multirow{2}{*}{ Características } & \multicolumn{8}{|c|}{ Níveis de proficiência } \\
\hline & 200 & * & 240 & 260 & 280 & 300 & * & 340 \\
\hline $\begin{array}{l}\text { Especificidade } \\
\text { de pistas } \\
\text { problemáticas }\end{array}$ & Sim & - & Não & Não & Não & Não & - & Não \\
\hline $\begin{array}{l}\text { Convergência } \\
\text { de pistas } \\
\text { problemáticas }\end{array}$ & Sim & - & Sim & Não & Não & Não & - & Sim \\
\hline $\begin{array}{c}\text { Tradição do } \\
\text { papel } \\
\text { esperado }\end{array}$ & Sim & - & Sim & Sim & Não & Não & - & Sim \\
\hline $\begin{array}{c}\text { Especialização } \\
\text { do contexto }\end{array}$ & Não & - & Não & Não & Não & $\mathrm{Sim}$ & - & $\mathrm{Sim}$ \\
\hline $\begin{array}{l}\text { Quantidade de } \\
\text { dados }\end{array}$ & 9 & - & 7 & 8 & 8 & 6 & - & 4 \\
\hline
\end{tabular}

*não houve item representante desse nível

O item locado no nível de proficiência 200 apresentou uma situação de um paciente em pré-operatório de cirurgia cardíaca, sendo o diagnóstico de enfermagem mais provável ansiedade, medo ou enfrentamento ineficaz. Para o nível de proficiência 240, o item mais típico foi de um paciente com fratura de quadril, no qual foi oferecida uma quantidade um pouco menor de dados, quando comparado ao nível 200, com a hipótese diagnóstica mais provável de déficit no autocuidado. No nível de proficiência 260 o item típico apresentou a hipótese diagnóstica mais provável medo ou ansiedade, porém com pistas pouco específicas e pouco convergentes. No nível de proficiência 280 o item mais representativo foi de uma situação com a hipótese diagnóstica mais provável de angústia espiritual ou risco de angústia espiritual. Para o nível de proficiência 300 o item mais representativo tratava de um senhor idoso com queixa de jato fraco de urina cuja hipótese diagnóstica mais provável é de atividades de recreação deficientes. Finalmente, no nível de proficiência 340, a quantidade de dados foi a menor de todas com a hipótese diagnóstica mais provável de risco de vínculo pais/filhos prejudicado considerada a mais distante do papel tradicionalmente esperado pela enfermeira. 
Com a progressão do nível de proficiência, observou-se aumento no distanciamento das tarefas de cuidados tradicionalmente esperadas do profissional enfermeiro bem como um aumento na complexidade de inferência diagnóstica. Notase também, o predomínio de situações envolvendo a área psicossocial nos níveis mais altos de proficiência (Quadro 8).

Quadro 8 - Descrição dos níveis da escala de proficiência em raciocínio diagnóstico.

\begin{tabular}{|c|c|}
\hline Nível & Descrição dos níveis da escala \\
\hline 200 & $\begin{array}{c}\text { Nesse nível o enfermeiro/estudante é capaz de formular diagnóstico } \\
\text { relativo a papel tradicional da enfermagem, diante de } \\
\text { aproximadamente 9 dados, de situação não especializada, contendo } \\
\text { pistas problemáticas convergentes e específicas a uma área de } \\
\text { diagnóstico. }\end{array}$ \\
\hline 240 & $\begin{array}{c}\text { Esse nível requer as mesmas habilidades do anterior, além da } \\
\text { capacidade de lidar com pistas problemáticas pouco específicas a uma } \\
\text { área de diagnóstico. }\end{array}$ \\
\hline 260 & $\begin{array}{c}\text { Esse nível requer as mesmas habilidades do anterior, acrescidas da } \\
\text { capacidade de lidar com pistas problemáticas divergentes. }\end{array}$ \\
\hline 300 & $\begin{array}{c}\text { Esse nível requer as mesmas habilidades do anterior, acrescidas da } \\
\text { capacidade de lidar com dados que extrapolam os papéis } \\
\text { tradicionalmente esperados da enfermagem. }\end{array}$ \\
\hline 340 & $\begin{array}{c}\text { Esse nível requer as mesmas habilidades do anterior, acrescidas da } \\
\text { capacidade de lidar com dados de áreas especializadas. }\end{array}$ \\
& $\begin{array}{c}\text { Nesse nível o enfermeiro/estudante é capaz de lidar com dados } \\
\text { relativos a papel não tradicional da enfermagem, diante de poucos } \\
\text { dados, de situação especializada, contendo pistas problemáticas } \\
\text { convergentes e pouco específicas a uma área de diagnóstico. }\end{array}$ \\
\hline
\end{tabular}

\subsection{NÍVEIS DE PROFICIÊNCIA E VARIÁVEIS SELECIONADAS}

Os dados de caracterização da amostra estudada mostraram que o tempo de experiência profissional das enfermeiras variou de recém formadas a profissionais com 41 anos de formação e, quanto aos estudantes do curso de graduação, a maioria, 120 alunas $(56,6 \%)$ encontravam-se no $6^{\circ}$ semestre de graduação seguidas por 46 alunas $(21,7 \%)$ no $8^{\circ}$ semestre de graduação (Tabela 5). 
Tabela 5 - Características da amostra de respondentes do TRD segundo categoria, tempo de formação e semestre de graduação, São Paulo - 2002

\begin{tabular}{cc}
\hline Características & Freqüência (\%) \\
\hline Categoria & $142(39,2)$ \\
Enfermeira* & \\
Tempo formação (anos) & $13,9(8,1)$ \\
Média (DP) & $<1$ \\
Mínima & 41 \\
Máxima & $212(58,6)$ \\
Estudante de graduação* & \\
Anos de graduação & $32(15,1)$ \\
1 a 2 & $126(59,4)$ \\
2,5 a 3 & $52(24,5)$ \\
3,5 a 4 & $2(0,9)$ \\
4,5 &
\end{tabular}

*Faltantes $=8$

$\mathrm{Na}$ amostra estudada, a maioria dos respondentes posicionou-se entre os níveis de proficiência 180 e 185 e entre 190 e 200 (Figura 2).

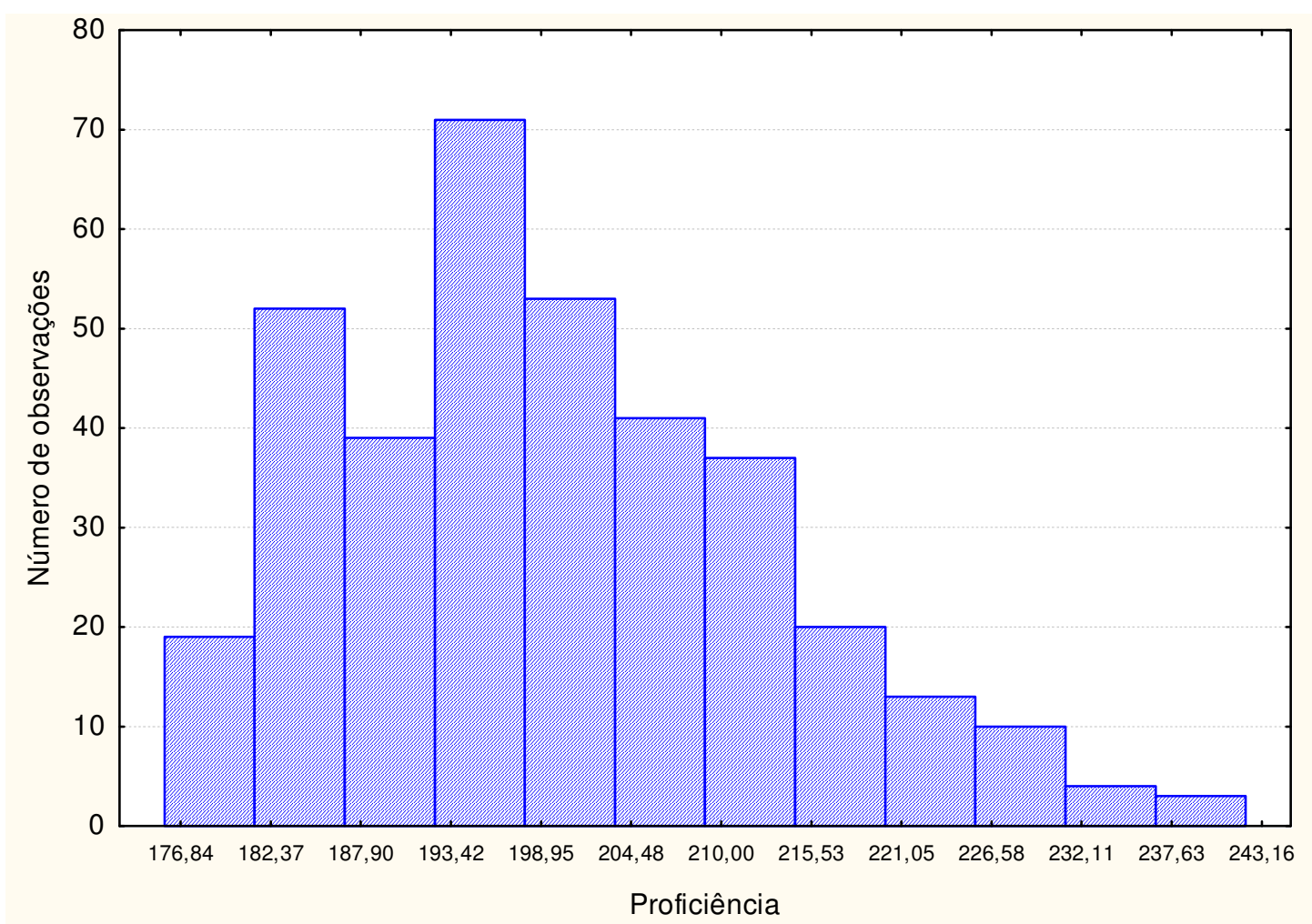

Figura 2 - Distribuição do nível de proficiência da amostra estudada. 
A associação entre a proficiência e a categoria do respondente, enfermeira ou estudante de graduação em enfermagem, não apresentou resultados significantes (Tabela 6).

Tabela 6 - Associação entre proficiência em raciocínio diagnóstico e categoria do respondente, São Paulo - 2007

\begin{tabular}{c|c|c|c}
\hline \multirow{2}{*}{ Proficiência } & \multicolumn{2}{|c|}{ Categoria* } & \multirow{2}{*}{$\begin{array}{c}\text { Valor } \mathrm{p} \\
(\text {-student })\end{array}$} \\
\cline { 2 - 3 } & $\begin{array}{c}\text { Enfermeiras } \\
(\mathrm{n}=142)\end{array}$ & $\begin{array}{c}\text { Alunas graduação } \\
(\mathrm{n}=212)\end{array}$ & \\
\hline Média (DP) & $199,74(13,65)$ & $200,27(13,27)$ & \\
Mediana & 196,16 & 200,76 & 0,717 \\
Variação & & & \\
Mín & 178,62 & 178,62 & \\
Máx & 239,41 & 235,02 & \\
\hline * faltantes = 8 & &
\end{tabular}

A proficiência média das enfermeiras e os anos de profissão estão representados na tabela abaixo (Tabela 7).

Tabela 7 - Distribuição da amostra de enfermeiros segundo faixas de tempo de formação e proficiência, São Paulo - 2007

\begin{tabular}{c|cc|c}
\hline \multirow{2}{*}{ Tempo de formação (anos) } & \multicolumn{2}{|c|}{ Proficiência } & \multirow{2}{*}{$\mathrm{n}(\%)$} \\
\cline { 2 - 3 } & Média & DP & \\
\hline $0-5$ & 202,81 & 15,05 & $25(17,6)$ \\
$6-10$ & 193,38 & 10,72 & $24(16,9)$ \\
$11-15$ & 202,53 & 14,91 & $32(22,5)$ \\
$16-20$ & 198,46 & 12,42 & $33(23,2)$ \\
$21-25$ & 201,62 & 15,43 & $19(13,4)$ \\
$26-30$ & 197,45 & 9,33 & $6(4,2)$ \\
$31-35$ & 201,53 & - & $1(0,7)$ \\
$36-40$ & 202,71 & - & $1(0,7)$ \\
$41-45$ & 201,32 & - & $1(0,7)$ \\
\hline Total & 199,74 & 13,65 & 142 \\
\hline
\end{tabular}


Pelo diagrama de dispersão pode-se observar que não houve evidência de correlação linear entre anos de profissão e a proficiência, pois o valor do $p$-nível foi de 0,970 (Figura 3).

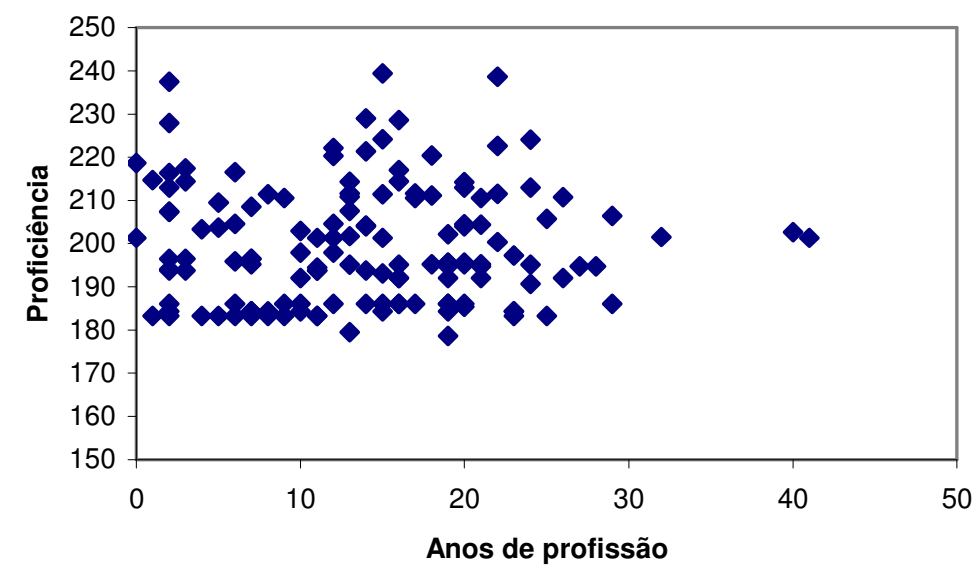

Figura 3 - Correlação entre nível de proficiência e anos de profissão, São Paulo 2007

As proficiências médias para a categoria estudantes de graduação em enfermagem segundo o tempo de graduação estão representadas na tabela abaixo (Tabela 8).

Tabela 8 - Distribuição da amostra de estudantes de enfermagem segundo faixas de tempo de graduação e proficiência, São Paulo - 2007

\begin{tabular}{c|cc|c}
\hline \multirow{2}{*}{$\begin{array}{c}\text { Tempo de } \\
\text { graduação (anos) }\end{array}$} & \multicolumn{2}{|c|}{ Proficiência } & \multirow{2}{*}{$\mathrm{n}(\%)$} \\
\cline { 2 - 3 } & Média & DP & \\
\hline $1,5-2$ & 203,40 & 14,74 & $32(15,1)$ \\
$2,5-3$ & 199,78 & 12,92 & $126(59,4)$ \\
$3,5-4$ & 199,43 & 13,39 & $52(24,5)$ \\
4,5 & 203,38 & 0,95 & $2(0,9)$ \\
\hline Total & 200,27 & 13,27 & 212 \\
\hline
\end{tabular}

Pelo diagrama de dispersão e pelo p-nível=0,204 do coeficiente de correlação linear observa-se que não houve correlação linear entre anos de graduação e proficiência (Figura 4). 


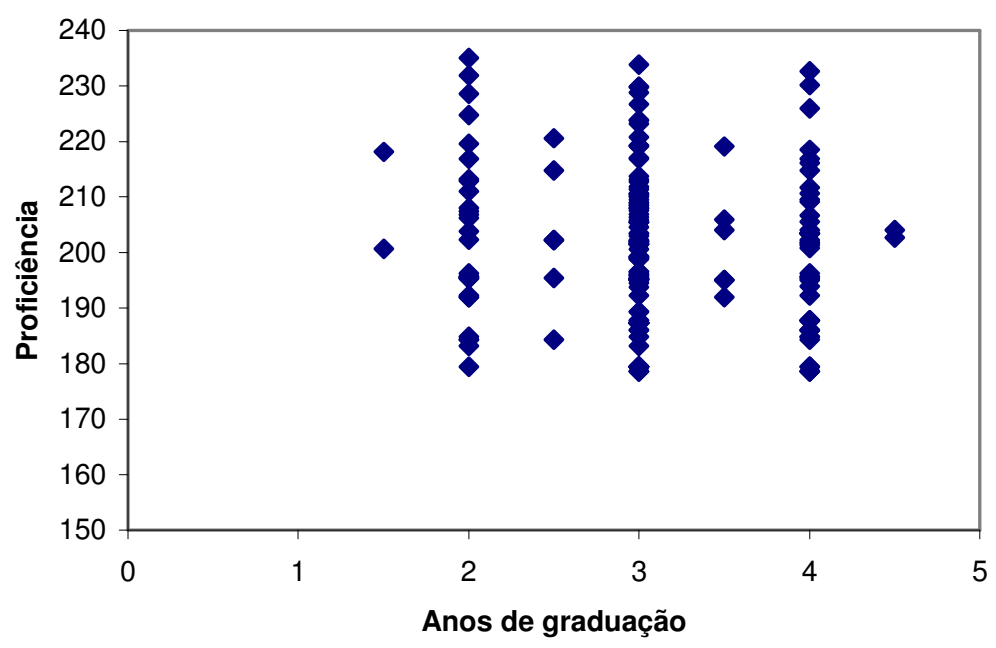

Figura 4 - Correlação entre nível de proficiência e anos de graduação, São Paulo 2007

Neste estudo, buscou-se avaliar se haveria associação entre o grau de contato com o diagnóstico de enfermagem e a proficiência em raciocínio diagnóstico. A Tabela 9 mostra as médias dos graus de contato segundo atividades e no geral.

Tabela 9 - Medidas dos graus de contato segundo atividades e categoria (enfermeira/estudante), São Paulo - 2002

\begin{tabular}{|c|c|c|c|c|c|c|}
\hline \multirow{2}{*}{ Categoria } & \multicolumn{2}{|c|}{ Alunos } & \multicolumn{2}{c|}{ Enfermeiros } & \multicolumn{2}{c|}{ Geral } \\
\cline { 2 - 7 } & Média & DP & Média & DP & Média & DP \\
\hline Leitura & 3,03 & 0,74 & 2,93 & 0,68 & 3,00 & 0,72 \\
Aula & 2,79 & 0,79 & 2,60 & 0,78 & 2,73 & 0,79 \\
Evento & 1,53 & 0,79 & 1,98 & 0,86 & 1,73 & 0,85 \\
Prática clínica & 2,73 & 0,97 & 2,21 & 1,06 & 2,52 & 1,04 \\
Pesquisa & 1,76 & 0,98 & 1,59 & 0,93 & 1,70 & 0,97 \\
Média geral & 2,37 & 0,86 & 2,27 & 0,86 & 2,33 & 0,87 \\
\hline
\end{tabular}

O coeficiente de correlação de Pearson entre a média de grau de contato com diagnóstico de enfermagem e a proficiência em raciocínio diagnóstico foi igual a $0,03(p=0,56)$ mostrando ausência de correlação (Figura 5). 


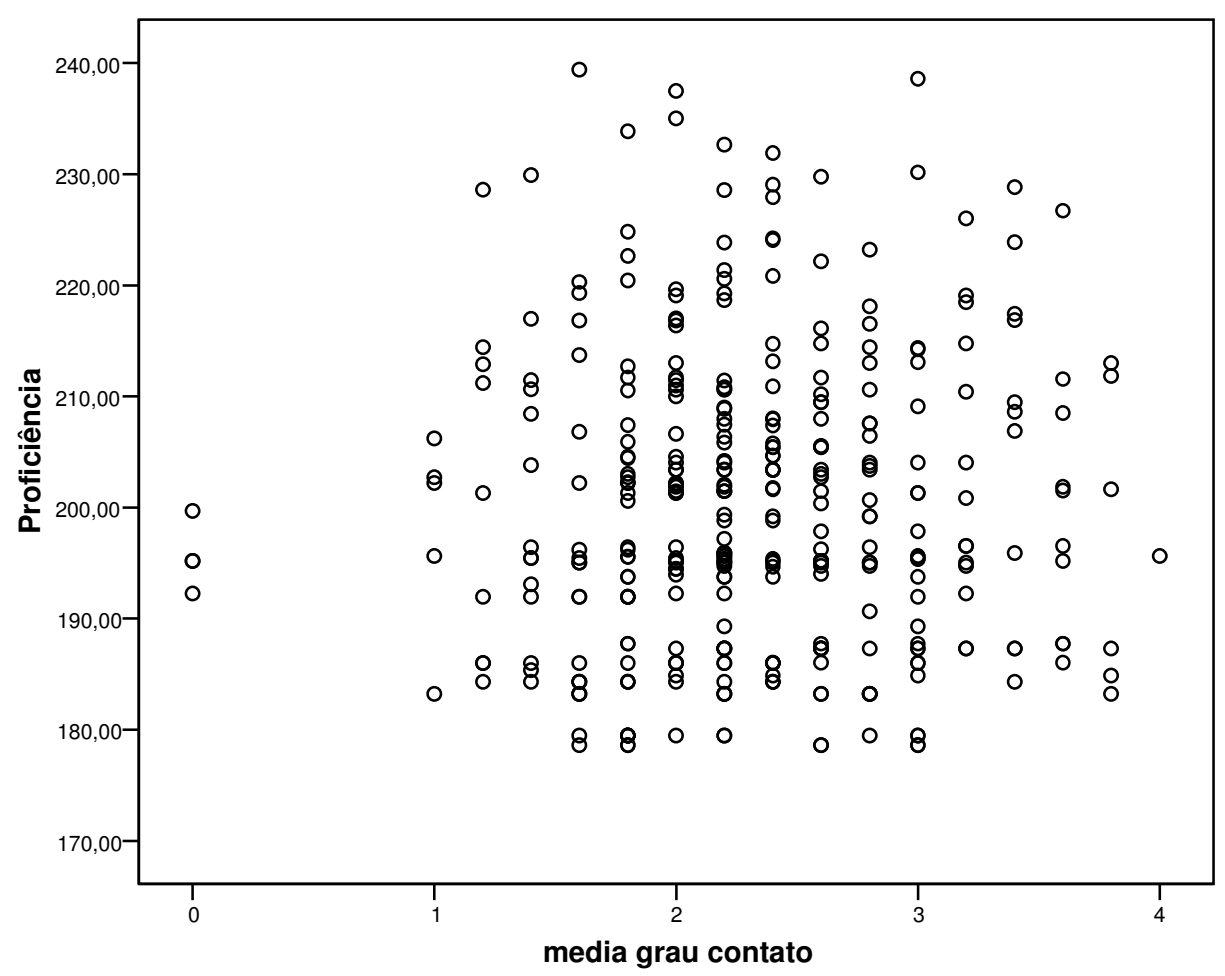

Figura 5 - Correlação entre o nível de proficiência e a média do grau de contato com o conceito diagnóstico de enfermagem, São Paulo - 2007

O Banco de Itens para Avaliação do Raciocínio Diagnóstico (BIARD) foi finalizado com a composição de um item locado no nível 200 da escala, sete itens no nível 240, onze itens locados no nível 260, seis itens no nível 280, cinco itens no nível 300 e um item no nível 340. 


\section{DISCUSSÃO}




\section{DISCUSSÃO}

As revisões da literatura, relacionadas à avaliação do raciocínio diagnóstico, mostraram resultados inconclusivos, no que diz respeito ao processo usado por profissionais de enfermagem, no levantamento de hipóteses diagnósticas ${ }^{8,13-26}$, em medidas de julgamento clínico $^{29-39}$, em métodos de ensino de habilidades de formulação diagnóstica ${ }^{8,40-42}$ e nos fatores correlatos ao desempenho em julgamento clínico $^{44-52}$. Poucos trabalhos apontaram resultados significativos ${ }^{22-24,27,40}$, indicando alguma metodologia de ensino ou de avaliação do raciocínio diagnóstico.

O presente estudo permitiu a criação de um banco de itens para avaliação do raciocínio diagnóstico, e também uma escala de avaliação do nível de proficiência para a interpretação dos itens e a identificação de padrões de proficiência.

Testes de simulação clínica são descritos em vários formatos, como: descrição escrita da situação de um paciente; apresentações de filmes ou gravações em videotape; representações de cenas com o uso de atores e testes interativos por meio de computador. O formato selecionado neste estudo foi um teste escrito de simulações clínicas que é o mais comumente utilizado ${ }^{12,35,39}$ para avaliações de raciocínio diagnóstico, porém parece haver certa controvérsia quanto ao teor desse formato. Para alguns autores ${ }^{29,31,32,39}$, esse tipo de teste não representa fielmente o que é encontrado na prática clínica real, as respostas elucidadas podem não ser como aquelas que ocorrem na prática, além de não possibilitar a observação do desempenho do indivíduo numa situação real de atendimento. Mas há estudos indicando sua utilização para o acesso de habilidades de resolução de problemas na área médica ${ }^{28,38}$, na enfermagem ${ }^{34-37}$ e em outras disciplinas ${ }^{39}$.

O fato de o processo de raciocínio clínico de enfermeiras não ter sido, ainda, descrito com clareza, gera dificuldade em como avaliar tal habilidade e, como conseqüência, dificuldades em se estabelecer o instrumento mais adequado para sua avaliação, mas as pesquisas têm mostrado mais resultados com instrumentos do tipo simulações escritas. Os testes de simulações escritas, que apresentam situações clínicas diversas, podem trazer problemas de avaliação para enfermeiras com especialização em determinada área, pois as questões tendem a ser generalistas e o 
profissional, a apresentar dificuldade em respondê-las. Isso nos leva a pensar na necessidade de instrumentos de avaliação específicos para cada especialidade.

No presente estudo, os 35 itens que compõem o DRT abrangem uma variedade de situações clínicas, com variável quantidade de dados oferecida em cada caso, cujas respostas, em cada parte do item, pretendem observar a habilidade do indivíduo em gerar hipóteses e a capacidade em selecionar o diagnóstico mais acurado.

Apesar do fato de esses itens terem sido elaborados com terminologia própria, por enfermeiras, foram baseados numa teoria desenvolvida em estudos realizados com médicos, portanto a extensão na qual esse modelo retrata o raciocínio diagnóstico de enfermeiras é desconhecida ${ }^{21}$.

A escala de avaliação do nível de proficiência variou do nível 120 ao nível 340 , sendo 200 o ponto médio, com intervalos de 20 graus. Os resultados mostraram que a maioria dos itens ficou locada em níveis mais altos da escala, permitindo que a escala fosse interpretada do nível médio para cima. Abaixo do nível 200 e no nível 220, nenhum item ficou locado. Isso implica na necessidade da construção de itens que possam discriminar os níveis mais baixos da escala e assim melhorar o seu poder de avaliação.

As habilidades aparentemente envolvidas na determinação dos níveis de proficiência estão relacionadas à complexidade de inferência exigida pelo conjunto dos dados apresentados e pela quantidade dos dados disponíveis ${ }^{11,18,27,79}$. A complexidade de inferência é uma preocupação dos investigadores, pelo fato de ser uma variável que influencia o processamento de informação ${ }^{19,21,80}$. O uso rotineiro de classificações que oferecem referência para as conclusões diagnósticas auxilia a ativação de hipóteses diagnósticas ${ }^{23,24}$.

Neste estudo, os itens mais fáceis, níveis 200 e 240, apresentam dados mais familiares ao trabalho rotineiro da enfermagem, são convergentes para uma ou poucas áreas problemáticas e não envolvem áreas muito especializadas de conhecimento. Para os itens locados nos níveis de proficiência 260 e 280, a quantidade de dados é menor que o nível 200, e os dados disponíveis são menos específicos e divergentes, remetendo a situações que extrapolam os papéis tradicionalmente esperados da enfermagem. Para o nível 300 da escala, o conjunto de 
dados apresenta menor quantidade de pistas disponíveis se comparado aos níveis anteriores, pistas estas divergentes e não específicas distantes do papel tradicional de atuação da enfermeira, exigindo atendimento especializado. Para o maior nível da escala os dados não são específicos, mas convergem para situações especializadas com a menor quantidade de dados entre os níveis.

As habilidades diagnósticas exigidas em cada nível de proficiência são cumulativas, pois os itens apresentam situações em que a natureza dos dados e a forma como o conjunto de dados é apresentado vão exigindo inferências mais complexas.

A habilidade no levantamento de dados é elemento importante na habilidade diagnóstica, pois, à medida que os dados vão sendo gerados, mais problemas podem ser hipotetizados e a relevância dos dados pode influenciar na acurácia diagnóstica. Portanto, decidir que dados coletar é elemento importante para a tarefa diagnóstica. Obter muitos dados sem que haja certo direcionamento para o uso dos mesmos pode complicar a tarefa. Por outro lado, buscar dados relevantes para confirmar ou negar hipóteses conscientemente estabelecidas pode facilitá-la. No estudo de Cianfrani ${ }^{18}$, a quantidade de dados influenciou a quantidade de problemas levantados por estudantes de graduação e por enfermeiras de cuidados críticos, e a relevância dos dados influenciou a acurácia. Quanto mais dados, mais problemas foram hipotetizados e mais tempo foi gasto na identificação desses problemas, a baixa relevância de dados levou à diminuição da acurácia e os erros foram influenciados, tanto pela quantidade, quanto pela relevância dos dados. No estudo de Broderick e Ammentorp $^{27}$, estudantes de graduação e enfermeiras foram avaliadas quanto ao comportamento de processamento de informação e, de acordo com os resultados, as enfermeiras solicitaram mais informações sobre os pacientes principalmente para sinais vitais, dor e avaliação neurológica. Gordon ${ }^{11}$, num estudo para identificação de estratégias usadas por enfermeiras em selecionar ou eliminar hipóteses no processo de declaração de um diagnóstico, mostrou que as enfermeiras foram mais acuradas em situações de quantidades de dados restritas, do que em situações nas quais a quantidade de dados era irrestrita e as enfermeiras mais acuradas terminaram o teste mais rapidamente que as enfermeiras menos acuradas. 
Grier $^{79}$ sintetizou o conhecimento sobre o processamento de informação feito para tomar decisões sobre o cuidado do paciente e os resumiu em coleta, organização, uso e estocagem. A pesquisa em coleta de dados em enfermagem parece abranger três aspectos, o primeiro, é a identificação das características do paciente com relação a quais informações são necessárias, outro, é a organização da coleta de dados e, por fim, a aquisição dos dados, através da observação e medida.

O fato de, neste estudo, não ter havido diferença de desempenho entre enfermeiras e estudantes não era o esperado, pois se acredita que a experiência deveria ter um importante papel no raciocínio diagnóstico ${ }^{9,81,82}$. Das pesquisas que utilizaram o mesmo tipo de testes de simulação clínica, dois estudos apresentaram amostras de estudantes e enfermeiras ${ }^{21,52}$, cujos resultados mostraram a ativação de inferências mais complexas por parte de enfermeiras ${ }^{21}$ e uma diferença relativamente baixa na habilidade de tomada de decisão entre enfermeiras de saúde pública e alunos $^{52}$. Dos estudos que usaram simulações com filmes, Davis ${ }^{44,45}$ utilizou a mesma metodologia com tamanhos de amostras diferentes e encontrou que a quantidade e a qualidade do cuidado oferecido pela enfermeira, foram superiores ao do oferecido pelos estudantes.

O desempenho entre as enfermeiras também não apresentou diferença com o aumento dos anos de profissão, cuja média foi de 13,9 anos (Tabela 5). Na literatura, há relatos ${ }^{44,45}$ de declínio na qualidade e quantidade do cuidado de enfermagem com o aumento dos anos de experiência, exceto pelas enfermeiras que, continuamente, evoluíram sua eficiência profissional e procuraram educação adicional, após três ou quatro anos de experiência clínica. Dois estudos da mesma autora ${ }^{22,23}$ mostraram resultados diferentes: um deles ${ }^{23}$, avaliou as abordagens de planejamento de enfermeiras, experientes e novatas, de hospital psiquiátrico e utilizou a teoria do processamento de informação, com uma metodologia de resposta escrita e verbal para três estudos de caso. Nenhuma relação foi encontrada entre a abordagem geral usada e a complexidade dos casos, a qualidade dos planos de cuidados das novatas foi melhor do que das experientes nos estudos de casos menos complexos ${ }^{23}$. No estudo de caso mais complexo, as enfermeiras experientes apresentaram melhor qualidade de planejamento ${ }^{23}$. No outro estudo ${ }^{22}$, realizado com a mesma amostra e metodologia do estudo anterior, avaliou a relação entre complexidade da tarefa e o 
processo de planejamento das ações, cujos resultados mostraram que as enfermeiras experientes produziram mais ações relacionadas às drogas e descreveram mais detalhadamente ações alternativas que as novatas, mas a proporção de ações alternativas avaliadas variou de acordo com a complexidade da tarefa. Hansen e Thomas $^{52}$, em 1969, consideraram inesperado o fato de enfermeiras de serviços de saúde pública, com educação profissional mais completa, não apresentarem desempenho superior ao de enfermeiras menos preparadas, com relação às decisões que envolviam cuidados médicos.

A proficiência entre os estudantes também não apresentou diferença, conforme os anos de graduação. Numa pesquisa ${ }^{56}$ que envolveu universidades com currículos diversos, dos duzentos planos de cuidados realizados por estudantes do último ano de graduação, apenas $28 \%$ atingiram todos os critérios de formulação de diagnósticos de enfermagem e 35\% não atingiram nenhum dos critérios. O estudo de Tanner $^{8}$, realizado com estudantes de diferentes períodos do curso de graduação em enfermagem, mostrou uma relação moderadamente baixa entre o número de hipóteses geradas e a acurácia diagnóstica.

No presente estudo, os itens selecionados para a composição do banco foram considerados difíceis, visto suas localizações na escala de avaliação. Talvez esse seja um fator que dificultou a discriminação entre as categorias enfermeira e estudante de enfermagem. Outro fator pode ser que a amostra avaliada tenha pouca familiaridade com o processo de ativação de hipóteses diagnósticas por falta do uso rotineiro de classificações em enfermagem o que também reflete que as enfermeiras e estudantes têm desenvolvido, absorvido e exercido muito pouco do seu papel profissional como diagnosticadores. Um terceiro argumento para a não discriminação entre as categorias, poderia ser que as situações propostas nos itens são diferentes da nossa realidade, visto que eles foram desenvolvidos por profissionais com experiências sócio-culturais diferentes das nossas.

O uso da teoria de resposta ao item (TRI), como medida de testes com itens e desenvolvimento de escalas na área da enfermagem é ainda incipiente ${ }^{83-88}$. Apesar do fato de a TRI ter sido originalmente aplicada à área da educação, sua aplicação em testes de personalidade, atitudes comportamentais e diagnóstico tem crescido muito nos últimos $\operatorname{anos}^{76}$. Neste estudo a TRI procurou explicar o nível de 
desempenho diagnóstico de um indivíduo, de acordo com a escala estabelecida, a partir dos acertos e erros. Mas, o fato de essa medida não diferir o nível de proficiência em raciocínio diagnóstico entre enfermeiras e estudantes de graduação em enfermagem, ou, entre as enfermeiras, aquelas com mais anos de profissão e, entre os alunos, aqueles que têm maior tempo de graduação, pode sugerir problemas com o modelo. O uso de um modelo que lida somente com respostas dicotômicas pode levar à redução na quantidade de informação que cada item oferece. No caso deste estudo, o sistema de pontuação dos itens acabou limitando o acerto apenas à parte $\mathrm{B}$ do item, não considerando os outros desempenhos que o instrumento pretendia avaliar. É altamente indicado que, assim que possível, esses dados sejam avaliados com respostas ordinais trazendo mais informações dos itens.

Uma síntese das explanações apresentadas para os resultados obtidos envolve os seguintes fatores:

1) A hipótese de que a experiência tem um importante papel no raciocínio diagnóstico não é verdadeira;

2) O modelo ou o instrumento não foi satisfatório para medir proficiência em raciocínio diagnóstico;

3) Ocorreu algum problema na codificação das respostas dos itens;

4) Não há diferença de habilidades em raciocínio diagnóstico entre enfermeiras e estudantes.

Na coleta dos dados do estudo primário, os 35 itens foram distribuídos em 7 formulários, contendo dez itens cada. Isso quer dizer que os indivíduos não responderam aos mesmos itens, mas responderam a itens comuns. Independentemente do formulário que a pessoa respondeu, os resultados são comparáveis. Os modelos utilizados na TRI permitem ${ }^{76}$ :

- $\quad$ Variar o erro padrão do traço latente, segundo sua magnitude;

- Considerar medidas separadas, porém na mesma escala de medida, para a caracterização de indivíduos e de itens;

- $\quad$ Estimar o traço latente de um indivíduo, com base em apenas alguns itens, sem a necessidade da aplicação de todos os itens, eventualmente disponíveis; 
- $\quad$ Padronizar as escalas de estimação do traço latente e dos parâmetros de dificuldade dos itens, desta forma, quando algumas modificações no instrumento são necessárias, os traços latentes estimados para indivíduos que responderam a versões diferentes tornam-se comparáveis;

- $\quad$ Estimar parâmetros de itens com números de categorias diferentes (com escores diferentes), sem provocar um desbalanceamento na estimação do traço latente.

Os itens que fazem parte do banco elaborado têm o poder de discriminar habilidades diagnósticas de enfermeiras e estudantes de enfermagem, pois oferecem graus variáveis de dificuldade. A análise qualitativa dos itens permitiu identificar que os fatores envolvidos nos diferentes níveis de proficiência incluem a especificidade e convergência de pistas problemáticas, a tradição do papel esperado, a especialização do contexto e a quantidade de dados oferecidos em cada item e esses todos em várias combinações.

A proficiência em raciocínio diagnóstico é uma variável qualitativa e por isso difícil de ser incluída em estudos quantitativos e também de ser avaliada para finalidades de ensino. A escala criada permite quantificar o traço latente habilidade diagnóstica, e assim operacionalizar essa variável para finalidade de pesquisa, ensino e gerência de recursos humanos.

A grande contribuição da TRI é que os parâmetros dos itens não variam com a amostra. Isso quer dizer que, se um modelo se adapta a uma população, os itens terão os mesmos parâmetros para subgrupos de todas as populações ${ }^{74}$. Por isso, os itens do BIARD terão os mesmos graus de dificuldade e de discriminação, independente da amostra em que for aplicado. 
CONCLUSÃo 


\section{CONCLUSÃO}

Este estudo permitiu criar um banco de itens para a avaliação do raciocínio diagnóstico. Os parâmetros de dificuldade e discriminação obtidos pela TRI guiaram a definição de uma escala para interpretar as respostas aos itens do BIARD.

O Banco de Itens para Avaliação do Raciocínio Diagnóstico (BIARD) apresenta 31 itens que discriminam indivíduos com nível de proficiência entre 200 e 340, segundo escala que envolve a combinação de características da tarefa diagnóstica: especificidade de pistas problemáticas, convergência de pistas problemáticas, tradição do papel esperado, especialização do contexto e quantidade de dados disponíveis em cada item.

Os itens poderão ser utilizados para estimativa da proficiência de profissionais, que façam parte da equipe de uma instituição, como também para seleção de pessoal para desempenho de determinadas tarefas ou para avaliação de currículos de graduação, que tenham como meta o desenvolvimento de habilidades diagnósticas e em disciplinas de pós-graduação.

Para a avaliação, poderão ser selecionados quantos itens forem necessários, de acordo com o nível de proficiência de cada item ou pelo tipo de área a ser avaliada, visto que a avaliação pela TRI estima o traço latente do indivíduo, baseada em apenas alguns itens, sem a necessidade da aplicação de todos os itens disponíveis.

Uma limitação do estudo está no fato de a escala não possuir itens que discriminem indivíduos com níveis de proficiência abaixo de 200 e no nível 220 . Pelo fato de os itens discriminarem níveis altos de proficiência, faz-se necessária a criação de itens que discriminem níveis mais baixos de proficiência, para que a escala possibilite também a avaliação de níveis baixos de proficiência.

Não houve associação entre níveis de proficiência e variáveis selecionadas (categoria, tempo de formação, anos de graduação e contato com diagnóstico de enfermagem).

A escala desenvolvida merece destaque pela discriminação das habilidades diagnósticas requeridas para o acerto dos itens de cada nível. Outros estudos que 
verifiquem variáveis associadas à proficiência em raciocínio diagnóstico são necessários para ampliar o conhecimento dos processos de aquisição de habilidades diagnósticas. 


\section{REFERÊNCIAS}

1. Simmons B, Lanuza D, Fonteyn M, Hicks F, Holm K. Clinical reasoning in experienced nurses. West J Nurs Res. 2003;25(6):701-19.

2. Lee J, Chan ACM, Phillips DR. Diagnostic practice in nursing: a critical review of the literature. Nurs Health Sci. 2006;8(1):57-65.

3. Pesut DJ, Herman J. OPT: transformation of nursing process for contemporary practice. Nurs Outlook. 1998;46(1):29-36.

4. Elstein AS; Kagan N; Shulman LS; Jason H; Loupe MJ. Methods and theory in the study of medical inquiry. J Med Educ. 1972;47(2):85-92.

5. Elstein AS. Clinical judgment: psychological research and medical practice. Science. 1976;194(4266):696-700.

6. Elstein AS, Bordage G. Psychology of clinical reasoning. In: Dowie J, Elstein AS, editors. Professional judgment: a reader in clinical decision making. Cambridge. Cambridge University Press; 1999.p.109-29.

7. Carnevali DL. The diagnostic reasoning process. In: Carnevali DL, Mitchell PH, Woods NF, Tanner CA, editors. Diagnostic Reasoning in Nursing. Philadelphia: JB Lippincott 1984; 25-26.

8. Tanner CA. Instruction in the diagnostic process: an experimental study. In Kim MJ, Moritz D (Eds). Classification of nursing diagnoses: proceedings of the third and fourth national conferences. New York: McGraw-Hill 1982.p.145-52.

9. Tanner CA, Padrick KP, Westfall UE, Putzier DJ. Diagnostic reasoning strategies of nurses and nursing students. Nurs Res. 1987;36(6):358-63.

10. Gordon M. Nursing Diagnosis: Process and Application. $3^{\text {a }}$ ed. New York: McGraw-Hill; 1987.p.161-4.

11. Gordon M. Predictive strategies in diagnostic tasks. Nurs Res. 1980;29(1):39-45.

12. Tanner CA. Teaching clinical judgment. Annu Rev Nurs Res. 1987;5:153-73.

13. Hammond KR. Clinical inference in nursing: II. A psychologist's viewpoint. Nurs Res. 1966;15(1):27-38.

14. Hammond KR, Kelly KJ, Schneider RJ, Vancini M. Clinical inference in nursing: analyzing cognitive tasks representative of nursing problems. Nurs Res. $1966 ; 15(2): 134-8$.

15. Hammond KR, Kelly KJ, Schneider RJ, Vancini M. Clinical inference in nursing: information units used. Nurs Res. 1966;15(3):236-43. 
16. Hammond KR, Kelly KJ, Castellan NJ, Schneider RJ, Vancini M. Clinical inference in nursing: use of information-seeking strategies by nurses. Nurs Res. 1966;15:330-6.

17. Hammond KR, Kelly KJ, Schneider RJ, Vancini M. Clinical inference in nursing: revising judgments. Nurs Res. 1967;16(1):38-45.

18. Cianfrani KL, The influence of amounts and relevance of data on identifying health problems. In Kim MJ, McFarland GK, McLane AM, editors. Classification on nursing diagnoses: proceedings of the Fifth National Conference. St Louis: Mosby. 1984.p.150-61.

19. Mattews CA, Gaul AL. Nursing diagnosis from the perspective of concept attainment and critical thinking. Adv Nurs Sci. 1979;2(1):17-26.

20. Grier MR. Decision making about patient care. Nurs Res. 1976;25(2):105-10.

21. Westfall UE, Tanner CA, Putzier D, Padrick KP. Activating Clinical Inference:a component of diagnostic reasoning in nursing. Res Nurs Health. 1986;9(4):26977.

22. Corcoran SA. Planning by expert and novice nurses in cases of varying complexity. Res Nurs Health. 1986;9:155-62.

23. Corcoran SA. Task complexity and nursing expertise as factors in decision making. Nurs Res. 1986;35(2):107-12.

24. Baumann A, Bourbonnais F. Nursing decision making in critical care areas. J Adv Nurs. 1982;7(5):435-46.

25. Phillips LR, Rempusheski VF. A decision-making model for diagnosing and intervening in elder abuse and neglect. Nurs Res. 1985;34(3):134-9.

26. Pyles SH, Stern PN. Discovery of nursing gestalt in critical care nursing: the importance of the gray gorilla syndrome. Image. J Nurs Sch. 1983;15(2):51-7.

27. Broderick ME, Ammentorp W. Information structures: an analysis of nursing performance. Nurs Res. 1979;28(2):106-10.

28. McGuire $\mathrm{CH}$, Babbott D. Simulation technique in the measurement of problemsolving skills. J Educ Meas. 1967;4:1-10.

29. de Tornyay R. Measuring problem-solving skills by means of the simulated clinical nursing problem test. J Nurs Educ. 1968;5(8):3-8,34-5.

30. Dincher JR, Stidger SL. Evaluation of a written simulation format for clinical nursing judgment: a pilot study. Nurs Res. 1976;25(4):280-5. 
31. Farrand LL, Holzemer WL, Schleutermann JA. A study of construct validity: simulations as a measure of nurse practitioners' problem-solving skills. Nurs Res. 1982;31(1):37-42.

32. Holzemer WL, Resnik B, Slichter M. Criterion-related validity of a clinical simulation. J Nurs Educ. 1986;25(7):286-90.

33. Holzemer WL, Schleutermann JA, Farrand LL, Miller AG. A validation study: simulations as a measure of nurse practitioners' problem-solving skills. Nurs Res. 1981;30(3):139-44.

34. McIntyre HM, McDonald FJ, Bailey JT, Claus KK. A simulated clinical nursing test: development and testing of an instrument to assess problem-solving behavior of baccalaureate students. Nurs Res. 1972;21(5):429-35.

35. McLaughlin FE, Carr JW, Delucchi KL. Selected psychometric properties of two clinical simulated tests. J Med Educ. 1980;55(4):375-6.

36. McLaughlin FE, Carr JW, Delucchi KL. Measurement properties of clinical simulation tests: hypertension and chronic obstructive pulmonary disease. Nurs Res. 1981;30(1):5-9.

37. McLaughlin FE, Cesa T, Johnson H, Lemons M, Anderson S, Larson P, Gibson J. Nurses' and physicians' performance on clinical simulation test: hypertension. Res Nurs Health. 1979;2(2):61-72.

38. Goran MJ, Williamson JW, Gonnella JS. The validity of patient management problems. J Med Educ. 1973;48(2):171-7.

39. Page GG, Fielding DW. Performance on PMPs and performance in practice: are they related? J Med Educ. 1980;55(6): 529-37.

40. Aspinall MJ. Use of a decision tree to improve accuracy of diagnosis. Nurs Res. 1979;28(3):182-5.

41. Hamdi ME, Hutelmyer CM. A study of the effectiveness of an assessment tool in the identification of nursing care problems. Nurs Res. 1970;19(4):354-9.

42. de Tornyay $\mathrm{R}$. The effect of an experimental teaching strategy on problem solving abilities of sophomore nursing students. Nurs Res. 1968;17(2):108-14.

43. Mitchell PH, Atwood J. Problem-oriented recording as a teaching-learning tool. Nurs Res. 1975;24(2):99-103.

44. Davis BG. Clinical expertise as a function of educational preparation. Nurs Res. 1972;21(6):530-4.

45. Davis BG. Effect of levels of nursing education on patient care: a replication. Nurs Res. 1974;23(2):150-5. 
46. Frederickson K, Mayer GG. Problem solving skills: what effect does education have? Am J Nurs. 1977;77(7):1167-9.

47. Verhonick PJ, Nichols GA, Glor BAK, McCarthy RT. I came, I saw, I responded: nursing observation and action survey. Nurs Res. 1968;17(1):38-44.

48. Aspinall MJ. Nursing diagnosis-the weak link. Nurs Outlook. 1976;24(7):433-7.

49. Holzemer WL, McLaughlin FE. Concurrent validity of clinical simulations. West J Nurs Res. 1988;10(1):73-83.

50. Hansen AC, Thomas DB. A conceptualization of decision making: its application role and situation-related differences in priority decisions. Nurs Res. 1968;17(5):436-43.

51. Hansen AC, Thomas DB. Role group differences in judging the importance of advising medical care. Nurs Res. 1968;17(6):525-32.

52. Hansen AC, Thomas DB. Differences and changes in decision judgments within two role groups. Nurs Res. 1969;18(4):333-8.

53. Thomas DB, Hansen AC. Role group differences in assignment of priorities: a variable perspective interpretation. Nurs Res. 1966;15(1):12-9.

54. Thomas DB, Hansen AC. Multiple discriminant analysis of public health nursing decision responses. Nurs Res. 1969;18(2):145-53.

55. Koehne-Kaplan NS, Tilden VP. The process of clinical judgment in nursing practice: the component of personality. Nurs Res. 1976;25(4):268-72.

56. DeBack V. Students' ability to formulate nursing diagnoses and the curriculum model. ANS Adv Nurs Sci. 1981;3(3):51-66.

57. Follman J. Research on nurses' critical thinking: cul de sac? Nurs Educ. 2003;28(6):255-6.

58. Kintgen-Andrews J. Critical thinking and nursing education: perplexities and insights. J Nurs Educ. 1991;30(4):152-7.

59. Hickman JS. A critical assessment of critical thinking in nursing education. Holist Nurs Pract. 1993;7(3):36-47.

60. Beeken JE. The relationship between critical thinking and self-concept in staff nurses and the influence of these characteristics on nursing practice. J Nurs Staff Dev. 1997;13(5):272-8.

61. Duchscher JEB. Catching the wave: understanding the concept of critical thinking. J Adv Nurs. 1999;29(3):577-83. 
62. Hicks FD. Critical thinking: toward a nursing science perspective. Nurs Sci Q. 2001;14(1):14-21.

63. Perciful EG, Nester PA. The effect of an innovative clinical teaching method on nursing student's knowledge and critical thinking skills. J Nurs Educ. 1996;35(1):23-8.

64. Adams BL. Nursing education for critical thinking: an integrative review. J Nurs Educ. 1999;38(3):111-9.

65. Adams MH, Stover LM, Whitlow JF. A longitudinal evaluation of baccalaureate nursing students' critical thinking abilities. J Nurs Educ. 1999;38(3):139-41.

66. Girot EA. Gradute nurses: critical thinkers or better decision makers? J Adv Nurs. 2000;31(2):285-97.

67. Hartley D, Aukamp V. Critical thinking ability of nurses educators and nursing students. J Nurs Educ. 1994;33(1):34-5.

68. Van Eerden K. Using critical thinking vignettes to evaluate students learning. Nurs Health Care Perspect. 2001;22(5):231-4.

69. Roberts JD. Problem-solving skills of senior student nurses: an exploratory study using simulation. Int J Nurs Stud. 2003;37:135-43.

70. Bauwens EE, Gerhard GG. The use of the Watson-Glaser Critical Thinking Appraisal to predict success in a baccalaureate nursing program. J Nurs Educ. 1987;26(7):278-81.

71. Glaze JE. Reflection as a transforming process: students advanced nurse practitioners' experiences of developing reflective skills as a part of an MSc programme. J Adv Nurs. 2001;34(5):639-47.

72. López M. O processo diagnóstico nas decisões clínicas. Rio de Janeiro: Revinter; 2001.p.27.

73. Pasquali L. Teoria dos testes na psicologia e na educação. Ed. Vozes, 2003.

74. Andrade DF; Tavares HR; Valle RC. Teoria da Resposta ao Item: conceitos e aplicações. SINAPE, 2000.

75. North American Nursing Diagnosis Association (NANDA). Nursing Diagnoses: definitions \& classification 2005-2006. NANDA International; 2005.

76. Curi M. Análises de questionários com itens constrangedores [tese]. São Paulo: Instituto de Matemática e Estatística da Universidade de São Paulo, 2006. 
77. Oliva APV, Cruz DALM, Volpato MP, Hayashi AAM. Atitudes de alunos e enfermeiros frente ao diagnóstico de enfermagem. Acta Paul Enferm. 2005;18(4):361-7.

78. Carlson-Catalano J. A teaching method for diagnostic skill development. In Lunney M. Critical thinking and nursing diagnosis: case studies and analyses. Philadelphia: NANDA; 2001. p.44-65.

79. Grier M. Information processing in nursing practice. In $\mathrm{HH}$ Werley \& JJ Fitzpatrick editors, Annual Review of Nursing Research. New York: Springer Publishing. 1984;v.2.p.265-87.

80. Payne JW. Task complexity and contingent processing in decision making: an information search and protocol analysis. Org Beh Hum Perf. 1976;16(2):366-87.

81. Radwin LE. Research on diagnostic reasoning in nursing. Nur Diagn. 1990;1(2):70-7.

82. Benner P, Tanner C, Chesla C. From beginner to expert: gaining a differentiated clinical world in critical care nursing. Adv Nurs Sci. 1992;14(3):13-28.

83. Howard EP. Applying the rash model to test administration. J Nurs Educ. 1985; 24(8):340-3.

84. van Alphen A, Halfens R, Hasman A, Imbos T. Likert or rash? Nothing is more applicable than good theory. J Adv Nurs. 1994;20(1):196-201.

85. Yen M, Edwardson SR. Item-response theory approach in scale development. Nur Res. 1999;48(4):234-8.

86. Beck CT, Gable RK. Item response theory in affective instrument development: an illustration. J Nurs Meas. 2001;9(1):5-22.

87. Lee NP, Fisher WP. Evaluation of the diabetes self care scale: an illustration of the rash model of measurement. J Nurs Meas. 2002;10(3):171-85.

88. Dimitrov DM, Shelestak D. Psychometric analysis of performance on categories of client needs and nursing process with the NLN diagnostic readiness test. J Nurs Meas. 2003;11(3):207-23. 